\title{
Individual and situational factors related to undergraduate mathematics instruction
}

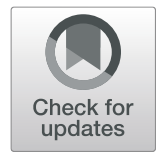

Estrella Johnson ${ }^{{ }^{*}}$, Rachel Keller ${ }^{1}$, Valerie Peterson ${ }^{2}$ and Timothy Fukawa-Connelly ${ }^{3}$

\begin{abstract}
Background: In the US, there is significant interest from policy boards and funding agencies to change students' experiences in undergraduate mathematics classes. Even with these reform initiatives, researchers continue to document that lecture remains the dominant mode of instruction in US undergraduate mathematics courses. However, we have reason to believe there is variability in teaching practice, even among instructors who self describe their teaching practice as "lecture." Thus, our research questions for this study are as follows: what instructional practices are undergraduate mathematics instructors currently employing and what are the factors influencing their use of non-lecture pedagogies? Here, we explore these questions by focusing on instruction in abstract algebra courses, an upper-division mathematics course that is particularly well positioned for instructional reform.

Results: We report the results of a survey of 219 abstract algebra instructors from US colleges and universities concerning their instructional practices. Organizing our respondents into three groups based on the proportion of class time spent lecturing, we were able to identify 14 instructional practices that were significantly different between at least two of the three groups. Attempting to account for these differences, we analyzed the individual and situational factors reported by the instructors. Results indicate that while significant differences in teaching practices exist, these differences are primarily associated with individual factors, such as personal beliefs. Situational characteristics, such as perceived departmental support and situation of abstract algebra in the broader mathematics curriculum, did not appear to be related to instructional differences.

Conclusions: Our results suggest that personal bounds in general, and beliefs in particular, are strongly related to the decision to (not) lecture. However, many of the commonly cited reasons used to justify the use of extensive lecture were not significantly different across the three groups of instructors. This lack of differentiation suggests that there may be relevant institutional characteristics that have not yet been explored in the literature, and a transnational comparison might be useful in identifying them.
\end{abstract}

Keywords: Instructional practice, Individual characteristics, Situational characteristics, Collegiate mathematics, Quantitative analysis

\section{Introduction}

In recent years, the discussion surrounding best practices in undergraduate mathematics instruction has increasingly featured calls for more active learning in both the United States (US) and internationally (e.g., Nardi, 2007 for a description of efforts in the UK). Professional societies in the US have uniformly voiced strong support for the use of active learning throughout the undergraduate program in numerous curricular guides. Synthesizing such reports in

\footnotetext{
* Correspondence: strej@vt.edu

'Virginia Tech, Blacksburg, VA, USA

Full list of author information is available at the end of the article
}

2015, the Common Vision Committee-a collaboration between the American Mathematics Association for TwoYear Colleges (AMATYC), the American Mathematical Society (AMS), the American Statistical Association (ASA), the Mathematical Association of America (MAA), and the Society for Industrial and Applied Mathematics (SIAM)-declared:

Across the guides we see a general call to move away from the use of traditional lecture as the sole instructional delivery method in undergraduate mathematics courses...Even within the traditional 
lecture setting, we should seek to more actively engage students than we have in the past... Oft-cited examples are active learning models where students engage in activities such as reading, writing, discussion, or problem solving that promote analysis, synthesis, and evaluation of class content. Cooperative learning, problem-based learning, and the use of case studies and simulations are also approaches that actively engage students in the learning process. (Saxe \& Braddy, 2015, p 19)

Even with these policy documents, researchers continue to document that lecture ${ }^{1}$ remains the dominant mode of instruction in US undergraduate mathematics courses (Eagan, 2016; Johnson, 2018). However, we have reason to believe there is variability in teaching practice, even among instructors who self describe their teaching practice as "lecture" (Johnson, Keller, \& Fukawa-Connelly, 2018). Thus, our research questions for this study are as follows: what instructional practices are undergraduate mathematics instructors currently employing and what are the factors influencing their use of non-lecture pedagogies? Here, we explore these questions by focusing on instruction in abstract algebra courses.

For many reasons, a first semester abstract algebra course is well suited for adoption of the type of active, non-lecture-based approaches called for above. In the US, these courses are normally taught in small sections (typically fewer than 40 students) consisting of junior and senior mathematics majors, with only a small proportion that will subsequently enroll in a follow-up course. It is common for at most a handful of sections to run per year, and thus, issues of coordination across multiple sections and instructors are few. More often than not, these courses are taught by tenured or tenuretrack professors who perhaps enjoy greater job security and more autonomy over course material than lecturers or itinerant faculty. Thus, many factors commonly used to justify the necessity of lecturing (e.g., content pressure, perceived student ability and interest, class size) are mitigated.

Additionally, the mathematics professional societies have voiced support for the use of active learning in abstract algebra courses. The Mathematical Association of America's Committee on the Undergraduate Program in Mathematics addressed abstract algebra specifically, saying that:

Although we refrain from specifying pedagogical practices, we do feel that active student engagement is necessary for a mastery of algebraic ideas. In particular, it is essential that students should wrestle with hard problems and communicate their solutions with care, in writing and in speaking. In addition, problem-based, inquiry-based and collaborative learning activities are appropriate means of maintaining student engagement.

(Isaacs, Bahls, Judson, Pollatsek, \& White, 2015)

Finally, in terms of reform initiatives targeting the upper-division mathematics courses, it is quite possible that none has received a comparable amount of attention as has abstract algebra. The Inquiry-Based Learning community and the MAA's Project NExT program are actively invested in abstract algebra (e.g., Ernst, 2016; Gallian et al., 2000; Hodge, Schlicker, \& Sundstrom, 2013), and four sets of curricular innovations have been developed by mathematics education researchers (Cook, 2014; Davidson \& Gulick, 1976; Dubinsky \& Leron, 1994; Larsen, Johnson, \& Weber, 2013b), all of which include efforts to incorporate student-centered pedagogy. Finally, the available research shows positive student outcomes (e.g., Larsen, Johnson, \& Bartlo, 2013a) for abstract algebra classes using active-learning approaches.

With many typically cited obstacles to change alleviated, abstract algebra offers in many ways a best-case scenario for the adoption of non-lecture pedagogy: factors which are typically understood as situational constraints (e.g., class size, coordinated courses) are absent, while at the same time, other situational affordances that may favor non-lecture pedagogy (e.g., availability of curricular innovations and supports, encouragement from professional societies, and supportive research findings) are available (see Henderson \& Dancy, 2007 for a list of constraints and supports of research-based instructional strategies). Nevertheless, in a previous study, we found that only 19 of the 126 abstract algebra instructors at research-intensive US universities stated that they "teach abstract algebra in a non-lecture format." We also found, however, that $64 \%$ of the respondents who think lecture is not the best way to teach still persist in lecturing (Johnson et al., 2018). With these findings in mind, the current study returns to this "best-case" context (abstract algebra) to investigate factors-both individual and situationalthat are (not) associated with different instructional profiles (e.g., lecturer or "something different").

The lecture stereotype of a teacher standing in front of the board with their back to their students, writing prepared notes, without soliciting or responding to student contributions is much maligned; however, it is also likely to be an overly exaggerated description of classroom practice (e.g., Paoletti et al., 2018). One problem with this depiction is that it suggests instructors must choose between two mutually exclusive pedagogical strategies: "lecture" and "not lecture." Forcing such a dichotomy dismisses the notion of an underlying continuum of practice and denies that there may be instructional techniques shared by "sages on the stage" and "guides on the side" (Wu, 1999). Thus, instead of sorting respondents' instructional practices into two disjoint bins (e.g., traditional or alternative), 
we decided instead to analyze instruction as a collection of practices implemented with varying degrees of frequency. With this pluralistic view, the extent to which an instructor lectures is just one element in a broader system of instructional practices.

To explore the complex interactions of instructional practice and related characteristics, we chose to utilize an a priori assignment of survey respondents into subgroups based on their self-reported use of lecture (as a percentage of their instructional time): extensive (lecturing more than $75 \%$ of the time), moderate (between 25 and $75 \%$ ), and limited (less than 25\%). The goal was to understand the extent to which this one instructional characteristic (the percentage of instructional time engaged in lecture) could be used to differentiate multiple facets of instructional practices. If the amount of time spent lecturing showed to be a discriminating factor, we then wished to determine whether the differentiation of the other variables (i.e., individual and situational factors) aligned with this a priori assignment in an attempt to understand their influence on pedagogical decisionmaking.

Specifically, we investigate three research questions in this report:

1) What is the range and distribution of reported instructional practices associated with instructors who report extensive, moderate, and limited use of lecturing in abstract algebra?

2) What individual characteristics (background, beliefs, knowledge, and goals) are associated with instructors who report extensive, moderate, and limited use of lecturing?

3) What situational characteristics are associated with instructors who report extensive, moderate, and limited use of lecturing?

\section{Related literature}

While undergraduate mathematics instructors in the US theoretically have significant autonomy with regard to pedagogical choices given tenure and the concept of academic freedom, we argue that they actually experience their teaching practice as constrained. That is, US mathematicians do not believe themselves to be free to teach however they please or adopt any curriculum that they choose. Instead, they balance a host of perceived responsibilities that include, but are not limited to, satisfying perceived obligations to their discipline, their institutions, their departments, and their students (Johnson, Caughman, Fredericks, \& Gibson, 2013; Roth McDuffie \& Graeber, 2003). As Hora (2012) argued, it is within these perceived contextual constraints that pedagogical decision-making and practice are shaped:
Importantly, organizational factors do not completely or automatically determine teaching practices; individual faculty exhibit a significant amount of agency and autonomy while making decisions about their professional lives (Stark, 2000). Thus, while complex configurations of organizational factors may shape the parameters of teaching practice, individual faculty actively negotiate, or make sense of, these contexts in customized ways as they make decisions about teaching (Henderson \& Dancy, 2007). (p. 208)

Thus, we view pedagogical decision-making as an instance of "choice-within-constraints" and we draw on the "new institutionalism" theories that have emerged from sociology, political science, and economics (Ingram \& Clay, 2000) as a lens for understanding how "actors pursue their interests by making choices within constraints" (pp. 525-526). We note a caveat that in the rest of this study, we do not distinguish between actual and perceived constraints because for the purposes of decision-making; the distinction is immaterial.

The first premise of new institutionalism theories is that actors (mathematics instructors, for our purposes) are rational and purposeful but also bounded in terms of their knowledge, worldview, and preferences (Hall \& Taylor, 1996). The broader literature on instructional decision-making, specifically the decision to lecture versus employ some alternative form of pedagogy, has long focused on individual characteristics, such as knowledge of research-based instructional practices (e.g., Henderson \& Dancy, 2009) and beliefs about teaching and learning (e.g., Calderhead, 1996). As Schoenfeld (1998) argued, beliefs strongly shape the teacher's decisions by constraining what seems possible. "Beliefs shape what they perceive in any set of circumstances, what they consider to be possible or appropriate in those circumstances, the goals they might establish in those circumstances, and the knowledge they might bring to bear in them" (p. 55). As a result, we hold that an individual's beliefs represent a particularly significant bound. Further, we posit that differentiating between beliefs and knowledge does not give additional insight into instructional decision-making (Calderhead, 1996).

Case studies of mathematics instructors at the undergraduate level, including abstract algebra, have uncovered multifaceted beliefs and goals that inform instructional practices (e.g., Johnson et al., 2013; Lew, FukawaConnelly, Mejia-Ramos, \& Weber, 2016; Speer, 2008; Weber, 2004). As to be expected, these beliefs about teaching and learning are as varied as the individuals possessing them. For instance, interview participants in one study, convinced of the virtue of non-lecture instruction, reported a desire to teach with "constructivist activities where the depth of knowledge is really greater" (Roth 
McDuffie \& Graeber, 2003, p. 336); however, others have argued that lecture is the only possible way to teach, especially in advanced mathematics courses (Wu, 1999).

While it is understandable that beliefs would vary by instructor, what is perhaps unexpected is the incongruity between those beliefs and pedagogical decision-making. For instance, a study by Johnson et al. (2018) found that $64 \%$ of respondents who think lecture is not the best way to teach lecture anyway. Operating under the assumption that mathematics instructors care deeply about their teaching-i.e., they want their students to learn, they are reflective about their pedagogy, and they are open to suggestions as to how to better achieve these goals (Alcock, 2010; Nardi, 2007; Weber, 2012)-it would follow that the incongruity between belief and practice is neither arbitrary nor unintentional.

This incongruity is not limited to undergraduate mathematics instructors. In looking at the research on teacher beliefs across $\mathrm{K}-16$ and in multiple STEM content domains (e.g., Eley, 2006; Fives \& Buehl, 2012; McAlpine, Weston, Berthiaume, \& Fairbank-Roch, 2006; Phillip, 2007), we found the evidence for the relationship between beliefs and teaching practice to be quite mixed. For instance, when looking at the teaching practices of 26 undergraduate mathematics instructors, Eley (2006) found that "the explicit use of higher level conceptions as a preliminary in the planning of specific teaching episodes was found not to have occurred at all consistently, or even frequently" (p. 208). This is echoed by Phillip (2007), who described an apparent inconsistency between K-12 teachers' expressed beliefs and their classroom practice. He concluded that teachers' beliefs about mathematics were more informative of practice than those about teaching and learning mathematics, that apparent inconsistencies were not so when viewed in a broader context, and that more general educational priorities often took precedence over those about mathematics and mathematics teaching. Furthermore, research in K-12 settings suggests that beliefs act to frame educators' problem spaces or conceptions of the teaching situation, but have less influence on actual classroom practices (e.g., Fives \& Buehl, 2012).

In making sense of the seeming contradiction that beliefs do not necessarily influence instructional practice, we start with the assumption that mathematics instructors are "complex, sensible people who have reasons for the many decisions they make" (Leatham, 2006, p. 92). This assumption necessitates that we as researchers look beyond the incongruity:

As observers (i.e., researchers), we may not find the resolution sensible. It may not seem logical, rational, justifiable, or credible. In fact, we may struggle to see how such clustering could have occurred. But our incredulity does not diminish another's coherence. As researchers, however, it is often difficult to look beyond the beliefs we assume must have been (or should have been) the predisposition for a given action ... observations of seeming contradictions are, in the language of constructivism, perturbations, and thus an opportunity to learn. (Leatham, 2006, p. 95)

As a way to understand how beliefs about teaching and learning influence instruction, we will consider how beliefs form, and exist within, complicated systems.

One way to view beliefs is to view them as a complex system organized by strength, quasi-logical relationships, and clustering (Leatham, 2006). While Leatham argues that the belief system is coherent for the individual believer, he also acknowledges it is not always possible for individuals to articulate their beliefs, nor are they always consciously aware of their beliefs. In other words, beliefs about teaching and learning might motivate an instructor's preferences regarding pedagogical style without a complete understanding of the influence or experience that propagated the belief. For example, "lecturers may harbor [sic] a number of contradictory beliefs and draw on them in their working lives, either to meet pragmatic demands or to justify their teaching practice" (Lea \& Callaghan, 2008, p. 174). Thus, pedagogical decisionmaking occurs within a complex system in which beliefs about teaching and learning must be reconciled with one's own ability to act on such an inclination.

Attending to the institutional and departmental context aligns with another major tenet of new institutionalism: that institutions "are defined as the rules, combined with their enforcement mechanisms, that constrain the choices of actors. These rules include the laws of states, the policies of organizations, and the norms of social groups" (Ingram \& Clay, 2000, p. 526). The research literature in undergraduate mathematics education has identified a number of ways in which policies and norms influence instructional decision-making.

Examples of institutional and departmental characteristics that shape undergraduate mathematics instruction include departmental expectations of content coverage, including those for subsequent courses (Hayward, Kogan, \& Laursen, 2016; Johnson et al., 2013; Roth McDuffe \& Graeber, 2003); time expectations (Hayward et al., 2016); promotion and tenure requirements (Hayward et al., 2016; Hora \& Ferrare, 2013); and class size (Benton \& Pallett, 2013). Yoshinobu and Jones (2012) have also discussed more subtle ways in which norms and expectations around instruction, pacing, and coverage have become omnipresent in undergraduate mathematics.

A significant issue we face as mathematics instructors is how to cover all the material. Mathematics teachers 
of all levels have some external and internal pressures to "get through" all the required material. Courses, such as calculus, are jam packed with content, and books are literally several hundred or even thousands of pages long. (Yoshinobu \& Jones, 2012, p. 303)

All of these institutional characteristics are typically described as constraining non-traditional instruction. One institutional characteristic that does seem to support the use of non-traditional instruction is the presence of a strong advocate who either holds a leadership position within the department or is otherwise highly socially respected (Hayward et al., 2016).

By attending to both the individual actor and the institution, we are better able to consider seemingly contradictory research findings. Take, for instance, the finding that some abstract algebra instructors simultaneously report (1) that they do not have time to redesign their course and (2) that their department would provide support to change their teaching in the form of "time to plan and redesign [their] course that would be supported and valued in [their] annual review or P\&T process" (Fukwa-Connelly, Johnson, \& Keller, 2016). Through the lens of new institutionalism, these results suggest that instructors may hold beliefs that bound their instructional practice and that there exist obligations and constraints that are enforced through social norms, if not through explicit policies.

In accordance with new insitutionalism, and in agreement with Turpen, Dancy, and Henderson (2016) who argued that "behavior is the result of the interplay between an individual's characteristics (e.g., beliefs, knowledge, attitudes, experience, etc.) and the environment in which that individual is located" (p.10), our study seeks to investigate possible relationships between individual characteristics and instructional practice and also between situational characteristics and instructional practice.

We view individual characteristics as directly related to the first premise of new institutionalism - that actors are bounded in terms of their knowledge, worldview, and preferences. In particular, we are especially focused on instructor beliefs about teaching and learning as such beliefs are prevalent in the research literature.

Further, we view situational characteristics, or "aspects outside of the individual instructor that impact, or are impacted by, the instructors' instructional practices" (Henderson \& Dancy, 2007, p. 10), to be manifestations of the second premise of new institutionalism (institutions constrain choices). These situational characteristics represent the institutional constraints (and affordances) placed on actors as they make decisions about their instructional practice. Here, we focus on the situational characteristics that are most commonly cited in the mathematics education literature, which include departmental expectations of content coverage, including those for subsequent courses (Hayward et al., 2016; Johnson et al., 2013; Roth McDuffie \& Graeber, 2003); time expectations (Hayward et al., 2016) and promotion and tenure requirements (Hayward et al., 2016; Hora \& Ferrare, 2013).

\section{Survey design, data, and methods Survey design}

In its purest form, the intention of our broader research project was to investigate the presentation of abstract algebra at the undergraduate level in the US. As this was a broad goal carried out in a context with relatively little prior research (i.e., instructional practices in upperdivision mathematics courses), the survey was designed for breadth and covered a myriad of topics. Inspiration for the survey format and item design came from two primary sources: the Characteristics of Successful Programs in College Calculus (CSPCC) surveys $^{2}$ and Henderson and Dancy's physics-education survey (Henderson \& Dancy, 2009). Informed by these existing instruments, and the available research literature on pedagogical decisionmaking, our survey included sections to assess each of the following types of information: teaching practice, individual characteristics (e.g., demographic information, beliefs about teaching, beliefs about students, interest in professional activities, knowledge of and openness to nonlecture practices), and situational factors (e.g., course/curriculum information, perceptions of departmental support). See Figs. 1 and 2 for sample items. ${ }^{3}$ Items were selected for inclusion based on relevance to the mathematics education literature and modified, if necessary, to suit our purposes (i.e., referring to abstract algebra and not calculus/physics instruction).

In addition to the research base used to inform the development of the survey items, validity evidence was gathered with respect to the components of Messick's (1992) validity framework. Specifically, content and substantive validity were addressed through expert review and structural validity was generalized from parallelism with the aforementioned existing survey instruments. In terms of the reliability of our survey, we had no way to corroborate the self-reported data with data from another rater (students, colleagues, chair, etc.) or for ourselves (e.g., using video data); however, this is a common limitation of research that relies on self-reported data. We direct interested readers to Johnson et al. (2018) for a more thorough discussion of the survey development.

\section{Data collection}

Administration of our survey took place over two rounds of sampling. In the first round, collected in the spring of 2015, we attempted a census of every university in the US 
Please indicate the approximate percentage of class time that you are:

Never

showing students how to

write specific proots
$0-25 \%$

○

$25-50 \%$

$50-75 \%$

$75-100 \%$

While teaching, approximately how many times per class meeting do you engage in the following practices?

Never

Once or Twice per class

3 or more times per class

I pause and ask students if

they have questions.

Please indicate the approximate number of times per term that you:

\begin{tabular}{|c|c|c|c|c|}
\hline & $\begin{array}{l}\text { Infrequently, } \\
\text { maybe a couple }\end{array}$ & & & More than once \\
\hline $\begin{array}{l}\text { Once per term } \\
\text { or not at all }\end{array}$ & $\begin{array}{c}\text { times per } \\
\text { month }\end{array}$ & $\begin{array}{c}\text { About once per } \\
\text { week }\end{array}$ & $\begin{array}{l}\text { About once per } \\
\text { class meeting }\end{array}$ & $\begin{array}{l}\text { per class } \\
\text { meeting }\end{array}$ \\
\hline
\end{tabular}

have students present a

proof (or counterexamples)

to the class

While teaching your course, how frequently do your students spend class time on the following (meaning, they're working alone or together on these without your explanation):

\begin{tabular}{lccccc} 
Never & $\begin{array}{c}\text { Sometimes } \\
\text { couple times a } \\
\text { semester) }\end{array}$ & $\begin{array}{c}\text { (approximately } \\
\text { once or twice } \\
\text { per month) }\end{array}$ & $\begin{array}{c}\text { Often } \\
\text { (approximately } \\
\text { once per week) }\end{array}$ & frequently \\
$\begin{array}{l}\text { Developing a definition or } \\
\text { exploring it's evolution }\end{array}$ & 0 & 0 & 0 & 0 & 0 \\
\hline
\end{tabular}

Fig. 1 Sample of teaching practice items

whose mathematics department offered either a Ph.D. or master's degree. ${ }^{4}$ The rationale for this decision was that these universities, in employing $57 \%$ of fulltime mathematics faculty, awarding $64 \%$ of the undergraduate degrees in mathematics, and accounting for $69 \%$ of the enrollment in advanced mathematics courses, represent the majority of both mathematics instructors and students (American Mathematical Society, 2016; Blair, Kirkman, \& Maxwell, 2013).

In the first round of data collection, survey requests were sent to departmental administrators. We asked the administrative assistants to forward the survey to any instructors who have taught abstract algebra, and we received 126 responses. To see details about, and results from, this initial study, please see Johnson et al. (2018).

In the spring of 2016, we decided to expand our sample, this time by targeting universities and colleges that offered a terminal bachelor's degree in mathematics. This decision was made upon observing that extant literature on teaching practices is primarily conducted by faculty residing at research-intensive universities and examines faculty teaching at such universities; it therefore fails to consider the experience of faculty whose foremost professional focus is teaching. It is possible that 
Chose the appropriate level of agreement with the following items:

\begin{tabular}{|c|c|c|c|c|}
\hline & Disagree & Slightly Disagree & Slightly Agree & Agree \\
\hline $\begin{array}{l}\text { I think lecture is the best } \\
\text { way to teach }\end{array}$ & $\circ$ & $\circ$ & $\circ$ & $\circ$ \\
\hline $\begin{array}{l}\text { I think lecture is the only } \\
\text { way to teach that allows } \\
\text { me to cover the necessary } \\
\text { content }\end{array}$ & $\circ$ & $\circ$ & $\circ$ & $\circ$ \\
\hline
\end{tabular}

How strong is your interest in:

\begin{tabular}{|l|cccc} 
& Very Strong & Strong & Weak & Very Weak \\
\hline Teaching abstract algebra & 0 & $\circ$ & $\circ$ & \\
\hline
\end{tabular}

If you wanted to make changes to the course you teach, do you believe you would have the following supp from your department/college:

\begin{tabular}{|l|l|l|} 
& Yes & Maybe \\
\hline $\begin{array}{l}\text { Time to plan and redesign } \\
\text { your course that would be } \\
\text { supported and valued in } \\
\text { your annual review or }\end{array}$ & & \\
P\&T process & & \\
\hline
\end{tabular}

Fig. 2 Sample of beliefs items

the lack of substantial representation of faculty at all types of institutions, especially teaching-focused faculty, limits our understanding of the collective instructional practices of mathematicians in proof-based courses. While it is true that doctoral-granting institutions do account for the majority of undergraduate degrees awarded in mathematics, the number of students earning undergraduate mathematics degrees outside of such institutions is non-trivial, and perhaps more importantly, the number of (undergraduate) abstract algebra courses offered outside of such institutions is significant. Furthermore, the omission of this subset of mathematics instructors likely excludes a key perspective from consideration based on the notion that the culture at teaching-focused schools might be better (or at least differently) suited for adopting non-lecture practices.

One reason for suspecting that practices vary across institution type is our hypothesis that the types of individuals employed by research universities are likely to have different beliefs about teaching and learning than their counterparts at teaching-focused colleges due to self-selection. This, coupled with the disparate expectations about time use, might influence an instructors' willingness to try non-traditional pedagogies. Faculty members at research institutions, faced with significant publication expectations, may have limited time to devote to teaching and course development and, perhaps, lack extensive peer support for experimenting with new pedagogy. Thus, there are reasons to believe that research based solely on instructors at research-focused institutions might underrepresent the range of teaching practices and the extent to which instructors are using non-lecture pedagogies.

In preparation for this second round of data collection, it was methodologically important that the items from the original survey remain largely unmodified. A few 
supplemental questions were added to the version sent to bachelor's-granting institutions, but the majority of items were a subset from the original survey (with formatting intact). A copy of the revised survey instrument can be found at the following link: pcrg.gse.rutgers.edu/ algebra-survey. For the purposes of this paper, only those items appearing on both versions of the survey were considered for analysis.

In the second round of data collection, the sampling frame consisted of the 909 US mathematics departments, as identified by the American Mathematical Society (2016) as awarding bachelor's degrees. Using a random number generator, a sample of 400 institutions was selected from this frame. The justification for this sample size was that our target response set was approximately 100-125 respondents (to achieve a balanced design with the responses from the first round survey) and the literature, coupled with our previous results, indicated we could expect a response rate of no more than $33 \%{ }^{5}$ As with the first round of recruitment, the intention was to contact departmental administrative assistants or department chairpersons and ask them to forward the survey to relevant faculty. In many instances, however, this information, and/or individual, was unavailable so instructors were contacted directly by the research team. Matching expectation, this sample yielded 112 responses, 91 of which were complete.

A study limitation that must be mentioned here is the fact that there is no reliable way to compute the response rate: our unit of analysis is individual instructors, but recruitment was done at the institutional level. In recruiting the second sample (from bachelor's-granting schools), we found it was quite often the case that departments comprised only a handful of faculty and possessed at most one instructor who taught abstract algebra; thus, a one-to-one correspondence between instructors and institutions is more likely in this sample (response rate of recruited $112 / 400 \approx 28 \%$, response rate total $112 / 909 \approx 12.3 \%$ ). In the case of schools granting graduate degrees, however, this one-to-one correspondence is likely not an accurate assumption, and therefore, the response rate is probably lower than was calculated $(123 / 330 \approx 37 \%)$. We acknowledge that the magnitude and imprecision of the response rate does inflate the sampling error; however, as low response is not necessarily a source of bias (Breakwell, Hammond, FifeSchaw, \& Smith, 2006), we found this sample suitable for analysis.

Another potential limitation of our sampling technique is the possibility that multiple instructors from a single institution may have participated, which would violate the underlying independence assumption. Institutional affiliation data was not gathered for our participants making the exact determination of cluster size impossible, so a post hoc estimation procedure was performed using the latitude/longitude data provided by Qualtrics. Analysis revealed that the proportion of singletons was in fact quite high and the distribution of responses did not warrant the use of a hierarchical modeling approach (in the first round survey, 83 of 88 locations were unique; in the second round, 110 of 126 locations were unique; average cluster size $=1.16 ; 5 / 214$ locations for which $n>2$ ).

Throughout this paper, all responses to applicable items have been combined into a single dataset and disaggregated by instructional type for analysis. Based on this characterization, 219 respondents were retained: 96 from bachelor's-granting institutions, 44 from master's-granting institutions, and 79 from Ph.D.-granting institutions.

\section{Methods}

This study has two main goals. The first is to determine the range and distribution of instructional practices as reported by abstract algebra instructors. Specifically, we are utilizing a priori assignments based on the respondents' self-reported use of lecture in accordance with the following prompt: Please indicate the approximate percentage of class time that you are lecturing. ${ }^{6}$ We classified our respondents as being one of three types of lecturers: "Extensive" (those who report lecturing 75$100 \%$ of the time), "Moderate" (those who report lecturing between 25 and $75 \%$ of the time), and "Limited" (those who never lecture combined with those who report lecturing $0-25 \%$ of the time). This taxonomy resulted in the following distribution of respondents: $17 \%$ Limited (38/219), 57\% Moderate (125/219), and 26\% Extensive (56/219). See Table 1 for details.

The decision to employ this a priori subgroup assignment was made for several reasons. First, even though we view the amount of time spent lecturing as just one element in a broader system of instructional practice, we believed it might be a particularly significant component. Obviously, as the amount of time spent lecturing decreases, the amount of time that could be used implementing alternative instructional techniques increases.

Table 1 Number of respondents cross-tabulated by institution type and lecture proclivity

\begin{tabular}{lllll}
\hline \multirow{2}{*}{$\begin{array}{l}\text { Terminal mathematics } \\
\text { degree }\end{array}$} & \multicolumn{4}{l}{ Reported amount of lecture } \\
\cline { 2 - 5 } & Limited & Moderate & Extensive & Total \\
\hline Bachelor's degree & 19 & 65 & 12 & 96 \\
Master's degree & 12 & 21 & 11 & 44 \\
Ph.D. & 7 & 39 & 33 & 79 \\
Total & 38 & 125 & 56 & 219 \\
\hline
\end{tabular}


However, questions remain about how instructors may choose to use their "non-lecture" instructional time. Thus, we wished to investigate the patterns of instructional practice within and between instructors grouped based on extensive, moderate, or limited use of lecture. This provided us insights into the extent to which other instructional practices were, or were not, associated with different rates of lecture.

Once respondents were binned based on the amount of time they report lecturing, we analyzed reports of instructional practice (e.g., whole class discussion, using diagrams to illustrate ideas) to identify similarities and differences between our groups of instructors. To address the first research question (concerning the range and distribution of instructional practices by amount of time spent lecturing), three surveys were analyzed. In each case, the prompt instructed respondents to indicate the prevalence of specific classroom activities or pedagogical practices utilized (via instances per term/instances per class meeting/percentage of class time).

The second goal was to detect the simultaneous presence of individual or situational factors associated with varying degrees of lecture usage (i.e., were there individual or situational factors that were similar within the groups of instructors and different between the groups). To address the second research question (concerning specific individual factors characteristic of each instructional type), five survey items were analyzed. The first two items solicited demographic information on respondents' teaching experience. Additionally, information was gathered pertaining to beliefs about teaching, beliefs about students, and interest in professional activities. In each instance, the prompt instructed respondents to indicate their level of agreement with a belief statement, or the strength of their interest in a professional activity, as measured on a Likert scale.

To address the third research question (concerning situational factors characteristic of each instructional type), eight survey items, divided into two subsets, were analyzed. The first subset situated abstract algebra within the respondent's broader mathematics curriculum, and the second subset was designed to capture respondents' perceptions of, departmental support for, and institutional constraints on instruction.

Group mean scores for each sub-item were computed by instructional type and compared using inference testing procedures such as ANOVA, chi-square, or the Kruskal-Wallis test, as applicable to the data, with post hoc testing for pairwise comparisons therein; within each item, the Bonferroni correction was applied to control for the family-wise error rate affiliated with multiple comparisons. Details applicable to particular tests can be found in the "Results and discussion" section.

\section{Results and discussion}

Research question \#1-what is the range and distribution of reported instructional practices associated with instructors who report extensive, moderate, and limited use of lecture in abstract algebra?

Recall that respondents were classified as being one of three types of lecturers: Extensive (those who report lecturing $75-100 \%$ of the time), Moderate (those who report lecturing between 25 and $75 \%$ of the time), and Limited (those who never lecture combined with those who report lecturing $0-25 \%$ of the time). In order to conceptualize the classroom experience of each group, the mean reported prevalence of a variety of pedagogical practices was computed and used as a means of comparison between the groups (Extensive, Moderate, Limited).

Categorizing instructors based on proportion of time spent lecturing allowed us to identify a number of teaching practices that did in fact vary between the three groups when employing the Kruskal-Wallis ${ }^{7}$ test as the global procedure with the Dunn-Bonferroni test of pairwise comparisons as the post-hoc analysis where indicated. When presented with a list of six pedagogical techniques (see Fig. 3), the reported frequency of usage was quite similar for the more conventional tactics, such as Asking Questions and Providing Explanations. There were significant differences between groups, however, when considering strategies that involved student participation, such as Having students engage in small group discussions or Having students ask each other questions. In these latter cases, the pattern of reported frequency was Limited $>$ Moderate $>$ Extensive, with all pairwise comparisons being significant.

Similar analysis of the next set of items (see Fig. 4) examined group differences based on the prevalence of particular mathematical activities (apart from taking notes) in which the instructor might ask the students to engage. This time, it was not frequency per class meeting but rather percentage of class time (in 25\% increments) that was reported. For all six ${ }^{8}$ items analyzed, significant differences were found for at least two, if not all three, pairwise comparisons. Instructors characterized as Extensive lecturers tended to favor teacher-centered activities (e.g., showing students how to write specific proofs), while the more student-centered activities (e.g., having students work together, having students give presentations) prevailed for those characterized as Limited lecturers.

In the final set of items (see Fig. 5), we eschewed data regarding individual class meetings in favor of a broader look at the course across the entire term. Instructors were asked to report the frequency (number of times per term) with which they asked their students to engage in particular mathematical work (e.g., Having students develop their 


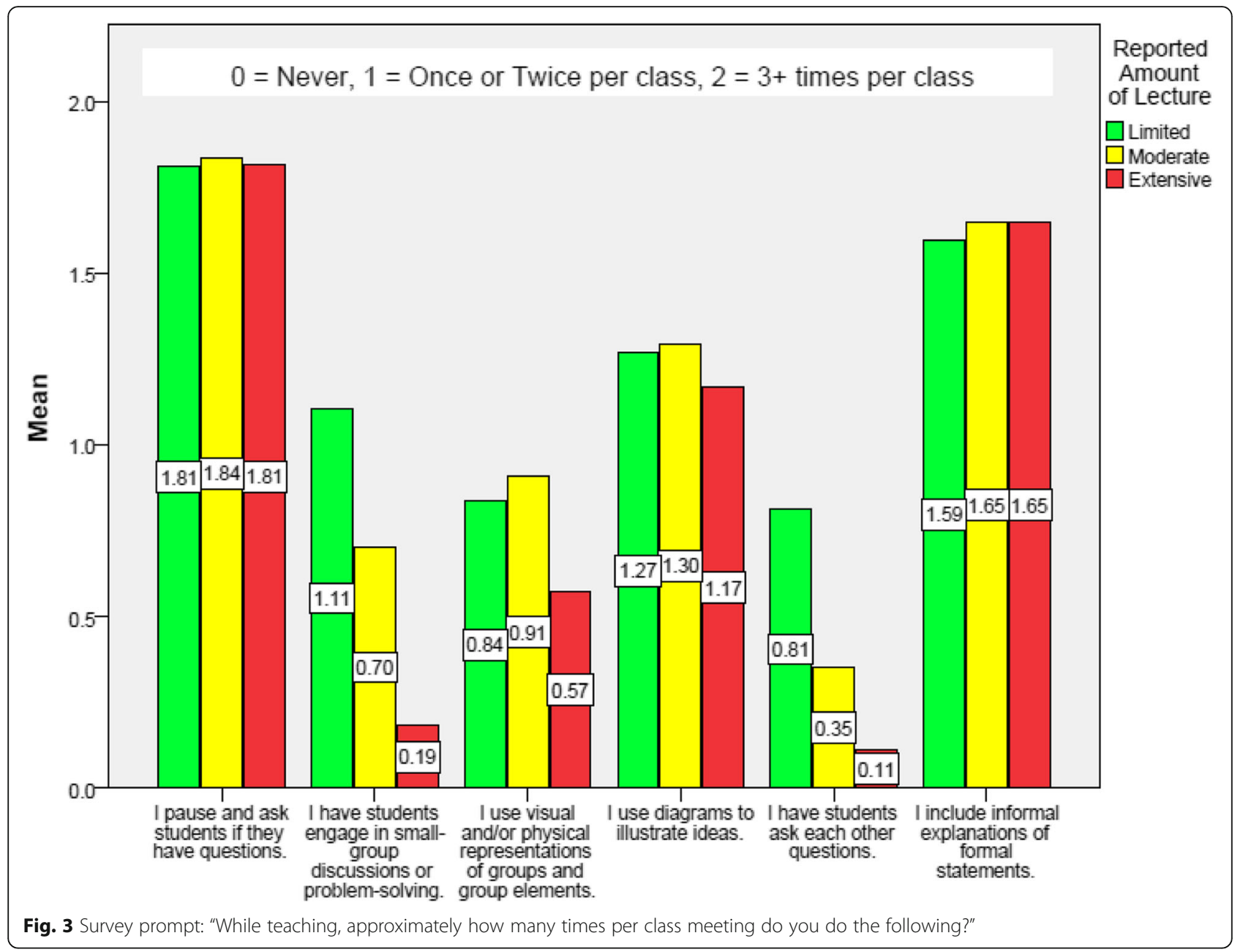

own proofs). Across all items, the pattern of reported frequency was Limited $>$ Moderate $>$ Extensive, with significant differences appearing in at least two of the pairwise comparisons.

We do not claim it is surprising that (with less time devoted to lecturing) instructors who employ moderate and limited use of lecture are spending more time engaging students in mathematical activity (e.g., developing proofs) and in peer-to-peer activity (e.g., working in small groups and giving presentations). Rather, we offer these results as evidence that our a priori decision to sort based on the amount of time lecturing was viable for differentiating instructional practice. As shown in Table 2, sorting respondents based on the amount of time lecturing highlighted 14 instructional practices that were significantly different between at least two of the three instructional categories, with six practices being significantly different on all pairwise comparisons across the three groups of instructors.

To aid in the interpretation of the group means presented in Figs. 3, 4, and 5, we also calculated the median response for instructors in the three groups (show in Table 3). In the Extensive lecturer group, there were a number of instructional practices with very strong agreement: $79 \%$ of respondents reported "never" having a whole class discussion, $89 \%$ reported "never" having students ask each other questions, 75\% reported "never" having students work together in small groups, $77 \%$ reported having students present a proof "once per term or less," and 86\% reported having students develop their own definition "once per term or less." There were no practices for the Moderate lecturers with such strong agreement; however, many items were agreed on by about $2 / 3$ of this group. This includes $68 \%$ reporting that they "never" have students ask each other questions and $68 \%$ reporting that they have their students explain their thinking for " $0-25 \%$ " of the class time. The Limited lecturers had the least amount of items with exact agreement. In fact, when the Limited lecturers agreed with each other, they also agreed with the Moderate and Extensive lectures. For instance, over $80 \%$ of the instructors in all three groups reported that they pause to ask 


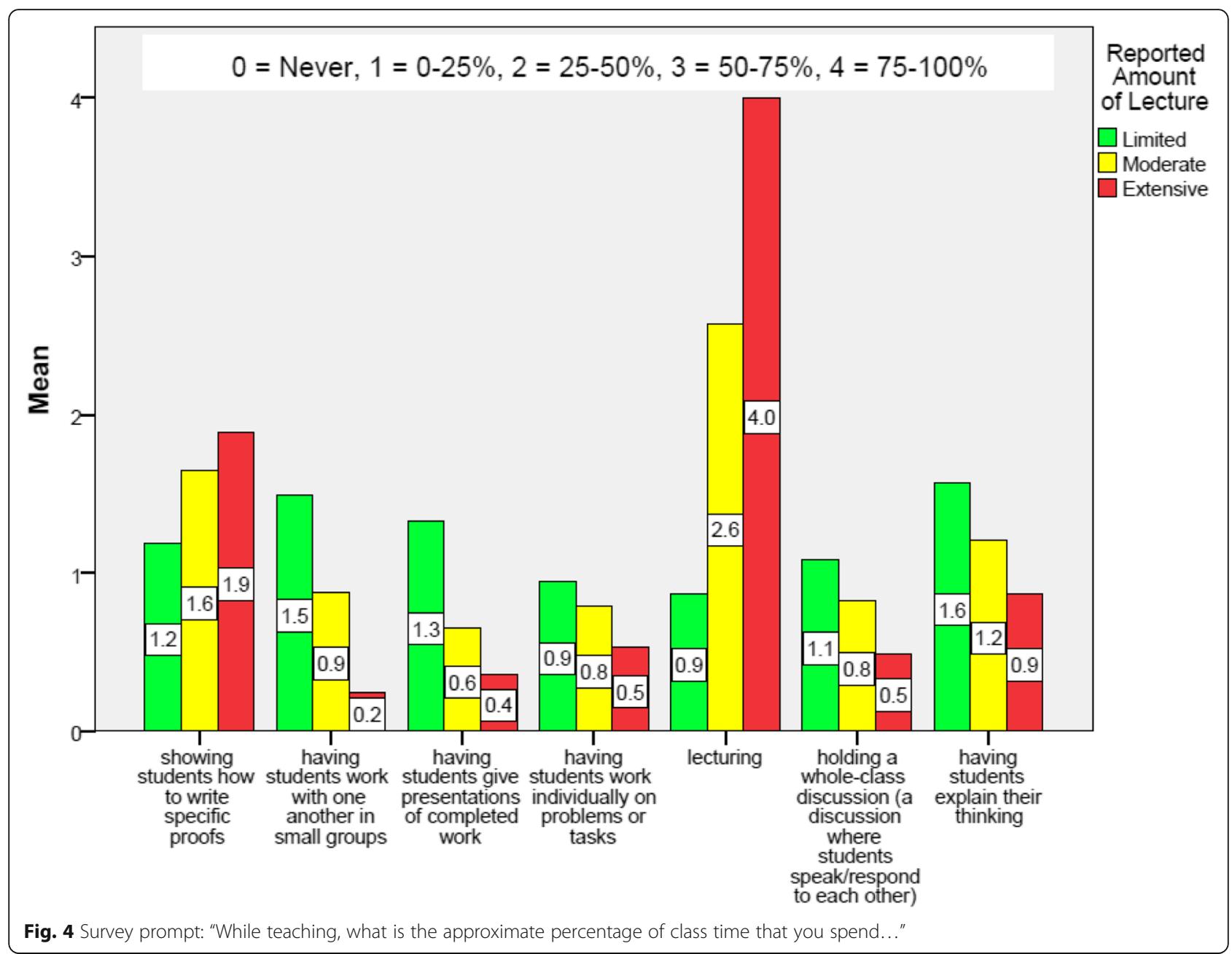

students questions " 3 or more times per class," a little more that $60 \%$ of instructors in all three groups use diagrams to illustrate ideas "about once or twice per class," and about $2 / 3$ of the instructors in all three groups reported that they include informal explanations of formal statements " 3 or more times per class."

Thus, when we sort instructors based on the amount of time spent lecturing, not only do we find significant differences in the amount of time spent engaged in other instructional practices, we also find differences in terms of the coherence and consistency within these groups. On many practices we see Extensive lectures reporting in very similar and consistent ways. This coherence lessens as the amount of lecture decreases, with Limited lecturers reporting very few uniform practices. Now that we have a way to understand how Extensive, Moderate, and Limited lecturers structure their classroom experience, we turn to identifying individual characteristics and situational factors that are associated with instructors in each defined instructional category.
Research question \#2-what individual characteristics (background, beliefs, knowledge, and goals) are associated with instructors who report extensive, moderate, and limited use of lecture?

In this portion of the analysis, we turn our attention to the individual characteristics that might explain why instructors fall into each of the three different instructional groups. Specifically, we focus on respondents' teaching experience, their beliefs about teaching and learning-particularly in the context of proof-based mathematics and abstract algebra-and their personal interest in a variety of professional activities.

First, in terms of teaching experience, Fig. 6 shows that all respondents had a considerable amount of teaching experience in general. The modal class for all three instructional approaches was six or more years' experience; however, the distribution across categories was dissimilar in favor of the Extensive lecturers. In terms of experience teaching abstract algebra specifically, the distribution of responses is more evenly dispersed. A significant difference was found across categories, with 


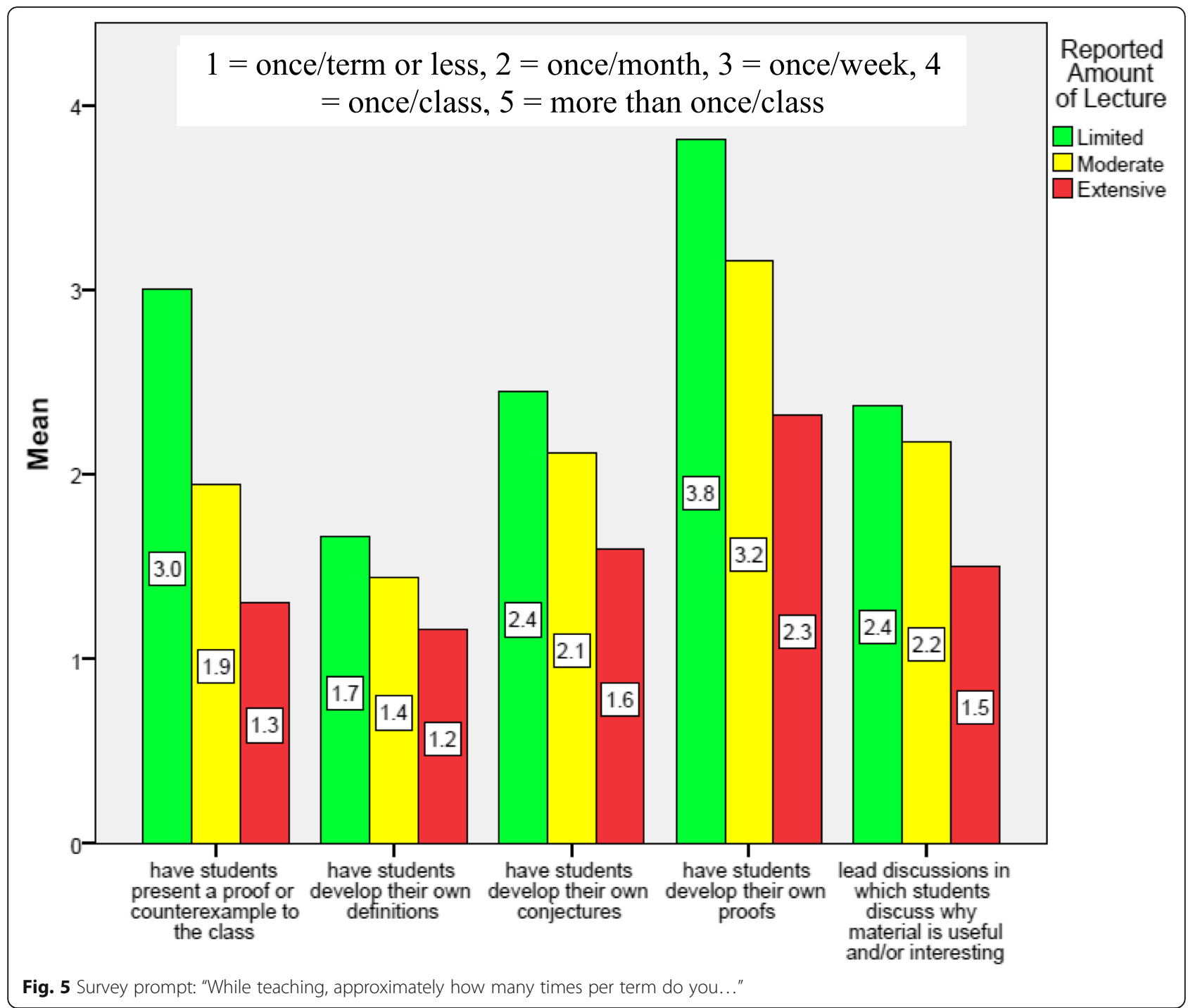

Extensive lecturers most likely to have taught the course upwards of eight times while Limited lecturers are most likely to have taught the class fewer than four times.

In terms of beliefs about teaching, the single most important difference between the three groups is, perhaps unsurprisingly, that Extensive lecturers reported the strongest agreement with the statement I think lecture is the best way to teach and with the related statement $I$ think lecture is the only way to teach that allows me to cover the necessary content. Significant differences were found on all three pairwise comparisons by instructional style (see Fig. 7); in particular, the Moderate group held a neutral position, neither agreeing nor disagreeing with the two aforementioned statements and the Limited lecturers actively disagreed with each claim.

In terms of other related beliefs, however, we found no significant difference between Extensive, Moderate, and Limited lecturers' reports of time constraints and pressure to cover material. Specifically, all three groups slightly disagreed that there was enough time for all the content they need or want to cover, and slightly agreed that there was enough time to help students understand difficult ideas. Moreover, no group reported a strong feeling of pressure to move quickly through the material. In fact, all groups reported relatively neutral feelings about time constraints. The agreement across groups is somewhat surprising as one of the common arguments against active learning is that less material can be covered than with lecture (e.g., Wu 1999). If Limited lecturers were able to cover less material than Moderate/Extensive lecturers, one might expect that they would experience more time pressure. However, what we found in our data was actually that Limited lecturers are reporting no more pressure to go through the material quickly than Extensive lecturers. So, while Extensive lecturers believe they must lecture to get through the material, Limited lecturers disagree, not only 
Table 2 Pairwise comparisons of instructional practices by instructional style

\begin{tabular}{|c|c|c|c|c|c|}
\hline \multirow[t]{2}{*}{ Fig. } & \multirow[t]{2}{*}{ Item } & \multirow[t]{2}{*}{ Global test statistics ${ }^{1}$} & \multicolumn{3}{|c|}{ Post hoc comparison ${ }^{2}$} \\
\hline & & & Extensive moderate & Extensive limited & Moderate limited \\
\hline \multirow[t]{6}{*}{3} & $\begin{array}{l}\text { I pause and ask students if they have } \\
\text { questions. }\end{array}$ & $H=.428, n=218, p=.808$ & $\mathrm{E} \sim \mathrm{M}$ & $E \sim L$ & $M \sim L$ \\
\hline & $\begin{array}{l}\text { I have students engage in small group } \\
\text { discussions or problem-solving. }\end{array}$ & $H=46.904, n=214, p<.001$ & $\mathrm{E}<\mathrm{M}(p<.001)$ & $\mathrm{E}<\mathrm{L}(p<.001)$ & $M<L(p=.006)$ \\
\hline & $\begin{array}{l}\text { I use visual and/or physical representations } \\
\text { of groups and group elements. }\end{array}$ & $H=10.366, n=219, p=.006$ & $\mathrm{E}<\mathrm{M}(p=.004)$ & $E \sim L$ & $M \sim L$ \\
\hline & I use diagrams to illustrate ideas. & $H=.958, n=218, p=.619$ & $E \sim M$ & $E \sim L$ & $M \sim L$ \\
\hline & I have students ask each other questions. & $H=23.720, n=219, p<.001$ & $\mathrm{E}<\mathrm{M}(p=.022)$ & $\mathrm{E}<\mathrm{L}(p<.001)$ & $M<L(p=.004)$ \\
\hline & $\begin{array}{l}\text { I include informal explanations of formal } \\
\text { statements. }\end{array}$ & $H=.035, n=219, p=.983$ & $E \sim M$ & $E \sim L$ & $M \sim L$ \\
\hline \multirow[t]{7}{*}{4} & $\begin{array}{l}\text { Showing students how to write specific } \\
\text { proofs. }\end{array}$ & $H=12.393, n=218, p=.002$ & $E \sim M$ & $E>L(p=.002)$ & $M>L(p=.013)$ \\
\hline & $\begin{array}{l}\text { Having students work with one another in } \\
\text { small groups. }\end{array}$ & $H=50.474, n=215, p<.001$ & $\mathrm{E}<\mathrm{M}(p<.001)$ & $\mathrm{E}<\mathrm{L}(p<.001)$ & $M<L(p=.005)$ \\
\hline & $\begin{array}{l}\text { Having students give presentations of } \\
\text { completed work. }\end{array}$ & $H=27.924, n=213, p<.001$ & $\mathrm{E}<\mathrm{M}(p=.006)$ & $\mathrm{E}<\mathrm{L}(p<.001)$ & $M<L(p=.003)$ \\
\hline & $\begin{array}{l}\text { Have students work individually on problems } \\
\text { or tasks. }\end{array}$ & $H=13.031, n=216, p=.001$ & $\mathrm{E}<\mathrm{M}(p=.009)$ & $\mathrm{E}<\mathrm{L}(p=.003)$ & $M \sim L$ \\
\hline & Lecturing & N/A & $E>M$ & $E>L$ & $M>L$ \\
\hline & Holding a whole class discussion. & $H=13.8, n=216, p=.001$ & $\mathrm{E}<\mathrm{M}(p=.039)$ & $\mathrm{E}<\mathrm{L}(p=.001)$ & $M \sim L$ \\
\hline & Having students explain their thinking. & $H=17.055, n=215, p<.001$ & $\mathrm{E}<\mathrm{M}(p=.007)$ & $\mathrm{E}<\mathrm{L}(p<.001)$ & $M \sim L$ \\
\hline \multirow[t]{5}{*}{5} & $\begin{array}{l}\text { Have students present a proof or counterexample } \\
\text { to the class. }\end{array}$ & $H=52.174, n=219, p<.001$ & $\mathrm{E}<\mathrm{M}(p<.001)$ & $\mathrm{E}<\mathrm{L}(p<.001)$ & $M<L(p<.001)$ \\
\hline & Have students develop their own definitions. & $H=11.302, n=219, p=.004$ & $\mathrm{E}<\mathrm{M}(p=.021)$ & $\mathrm{E}<\mathrm{L}(p=.005)$ & $M \sim L$ \\
\hline & Have students develop their own conjectures. & $H=18.426, n=219, p<.001$ & $\mathrm{E}<\mathrm{M}(p=.002)$ & $\mathrm{E}<\mathrm{L}(p<.001)$ & $M \sim L$ \\
\hline & Have students develop their own proofs. & $H=33.914, n=219, p<.001$ & $\mathrm{E}<\mathrm{M}(p<.001)$ & $\mathrm{E}<\mathrm{L}(p<.001)$ & $M<L(p=.013)$ \\
\hline & $\begin{array}{l}\text { Lead discussions in which students discuss } \\
\text { why material is useful and/or interesting. }\end{array}$ & $H=28.729, n=219, p<.001$ & $\mathrm{E}<\mathrm{M}(p<.001)$ & $\mathrm{E}<\mathrm{L}(p<.001)$ & $M \sim L$ \\
\hline
\end{tabular}

\footnotetext{
${ }^{1}$ The family-wise error rate for the global tests was controlled by use of the Bonferroni correction by cluster (i.e., 3, 4, 5). Post hoc testing was performed only in cases where this threshold for significance was achieved

${ }^{2}$ The $p$ values reported here have been adjusted with a Bonferroni correction. In the cases where "a $\sim$ " is used to describe a relationship, it does not mean that there is no ordering between the groups, but rather that it did not achieve the desired significance level. Furthermore, in cases where seemingly contradictory results appear (i.e. $M<E$ and $L \sim M$ should imply that $L<E$ but $L \sim E$ is reported), this is not to say that one cannot infer the ordered relationship but the power reduction caused by dissimilar sample sizes and the FWER correction does not allow for the reporting of the latter pairwise comparison with significance. We explain this to differentiate between describing trends (i.e., $\mathrm{L}<\mathrm{M}<\mathrm{E}$ ) versus declaring differences between groups. The former case does not necessarily achieve statistical significance, whereas the latter does
}

in practice-by virtue of their reduced lecture proclivitybut also in sentiment as they are not reporting additional negative feelings or dissatisfaction regarding their content coverage. Additionally, we found a lack of alignment between beliefs about time constraints and the perception that lecture is (or is not) the only way to cover content efficiently. All groups feel relatively neutral about time, tending to agree that there is not quite enough time to cover material in the course, yet Extensive and Limited lecturers report distinct ways of addressing this-strongly agreeing and disagreeing, respectively-that lecture is the only way to cover all necessary content.

In terms of beliefs about students, significant differences between the groups existed for all five survey items (see Fig. 8), often in ways that appear to be consistent with the reported teaching practices of the three instructional styles. For instance, Extensive lecturers not only agreed with the statement that lecture was the best way to teach, they also reported the highest mean agreement with the statement, I believe students learn better if I first explain the material to them and then they work to make sense of the ideas themselves. Limited lecturers, on the other hand, were the only group that disagreed with that statement. Instead, they showed the highest mean agreement with the statements I think students learn best if they do mathematical work in class and I think students learn better when they struggle with the material prior to me explaining the material to them. Interestingly, those instructors who lecture the most also reported the strongest disagreement 
Table 3 Homogeneity of instructional practices by group

\begin{tabular}{|c|c|c|c|c|c|c|c|}
\hline \multirow[t]{2}{*}{ Fig. } & \multirow[t]{2}{*}{ Item } & \multicolumn{2}{|l|}{ Limited } & \multicolumn{2}{|c|}{ Moderate } & \multicolumn{2}{|c|}{ Extensive } \\
\hline & & Mean $^{a}$ & Median $(\%)^{b}$ & Mean & Median (\%) & Mean & Median (\%) \\
\hline \multirow[t]{6}{*}{3} & Ask questions & 1.82 & $2(87 \%)$ & 1.84 & $2(86 \%)$ & 1.82 & $2(82 \%)$ \\
\hline & Small group discussions & 1.13 & $1(50 \%)$ & 0.7 & $1(51 \%)$ & 0.19 & $0(79 \%)$ \\
\hline & Visual representations & 0.82 & $1(55 \%)$ & 0.9 & $1(63 \%)$ & 0.59 & $1(48 \%)$ \\
\hline & Diagrams & 1.27 & $1(61 \%)$ & 1.28 & $1(58 \%)$ & 1.2 & $1(66 \%)$ \\
\hline & Students ask each other & 0.84 & $1(47 \%)$ & 0.35 & $0(68 \%)$ & 0.13 & $0(89 \%)$ \\
\hline & Informal explanations & 1.61 & $2(68 \%)$ & 1.63 & $2(67 \%)$ & 1.66 & $2(68 \%)$ \\
\hline \multirow[t]{7}{*}{4} & Showing proofs & 1.18 & $1(53 \%)$ & 1.62 & $2(46 \% @ 1)^{c}$ & 1.88 & $2(36 \% @ 1)$ \\
\hline & Small groups & 1.55 & $1(45 \%)$ & 0.9 & $1(45 \%)$ & 0.24 & $0(75 \%)$ \\
\hline & Student presentations & 1.32 & $1(53 \%)$ & 0.66 & $1(50 \%)$ & 0.36 & $0(66 \%)$ \\
\hline & Individual work & 1.03 & $1(58 \%)$ & 0.77 & $1(54 \%)$ & 0.52 & $0(61 \%)$ \\
\hline & Lecturing & 0.87 & $1(87 \%)$ & 2.57 & $3(57 \%)$ & 4 & $4(100 \%)$ \\
\hline & Whole class discussions & 1.08 & $1(42 \%)$ & 0.81 & $1(47 \%)$ & 0.48 & $0(55 \%)$ \\
\hline & Students explain & 1.63 & $1(53 \%)$ & 1.2 & $1(68 \%)$ & 0.87 & $1(63 \%)$ \\
\hline \multirow[t]{5}{*}{5} & Students present proofs & 3 & 3 (34\% @ 2) & 1.94 & $2(39 \% @ 1)$ & 1.3 & $1(77 \%)$ \\
\hline & Student definitions & 1.66 & $1(58 \%)$ & 1.44 & $1(66 \%)$ & 1.16 & $1(86 \%)$ \\
\hline & Student conjectures & 2.45 & $2(42 \%)$ & 2.11 & $2(34 \%)$ & 1.59 & $1(55 \%)$ \\
\hline & Students develop proofs & 3.82 & 4 (34\% @ 5) & 3.15 & $3(37 \%)$ & 2.32 & 2 (34\%@1) \\
\hline & Useful/interesting & 2.37 & $2(40 \%)$ & 2.18 & $2(42 \%)$ & 1.5 & $1(71 \%)$ \\
\hline
\end{tabular}

${ }^{\mathrm{a}}$ Mean the mean of the values on the Likert scale; listed for reference

${ }^{\mathrm{b}}$ Median the median of the values on the Likert scale, \% the proportion of respondents in a given group reporting this value

'The "@" symbol indicates that the modal class is not equivalent to the median; 2 (46\% @ 1) is properly interpreted as a median of 2 with a mode of 1 representing $46 \%$ of respondents

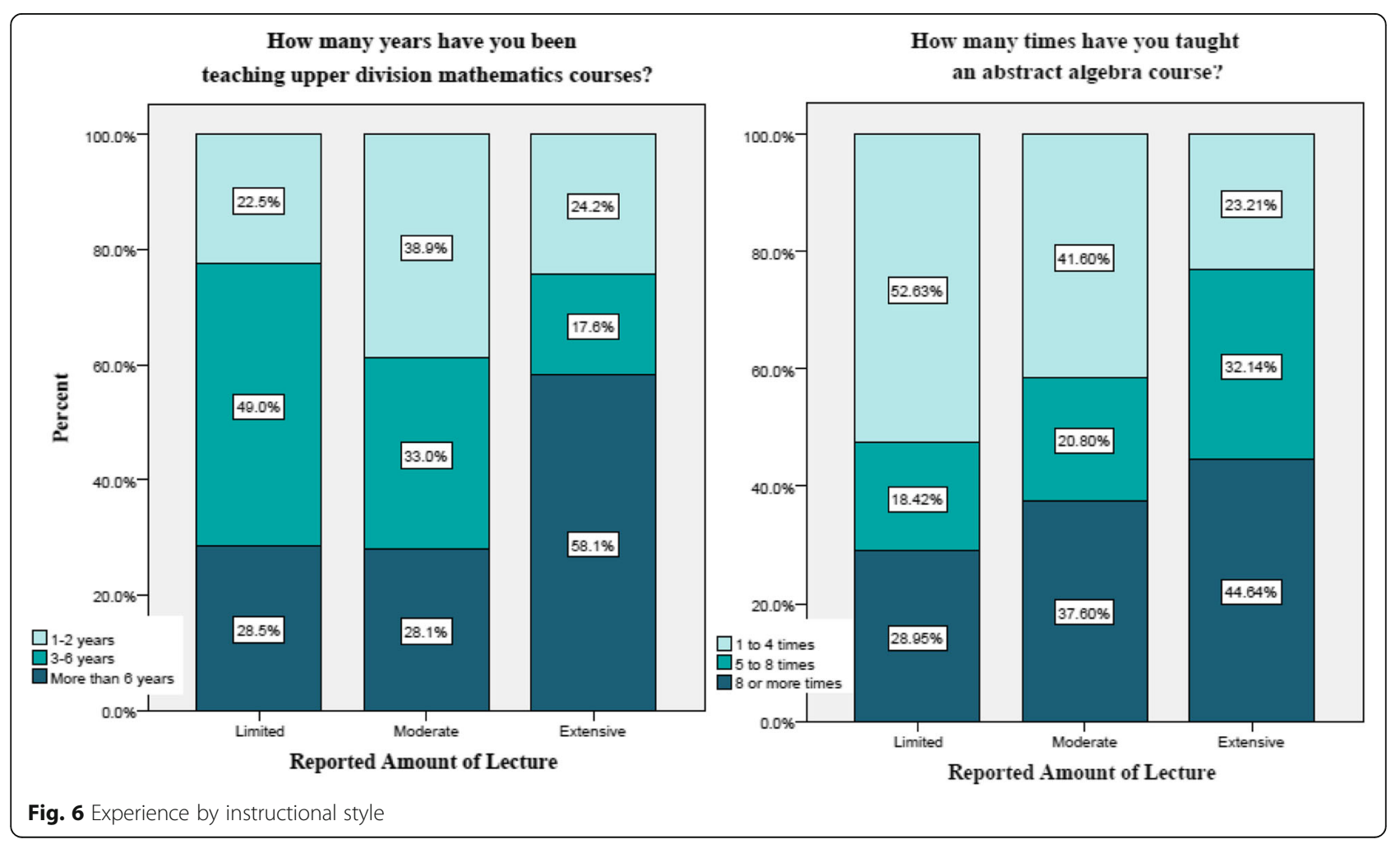




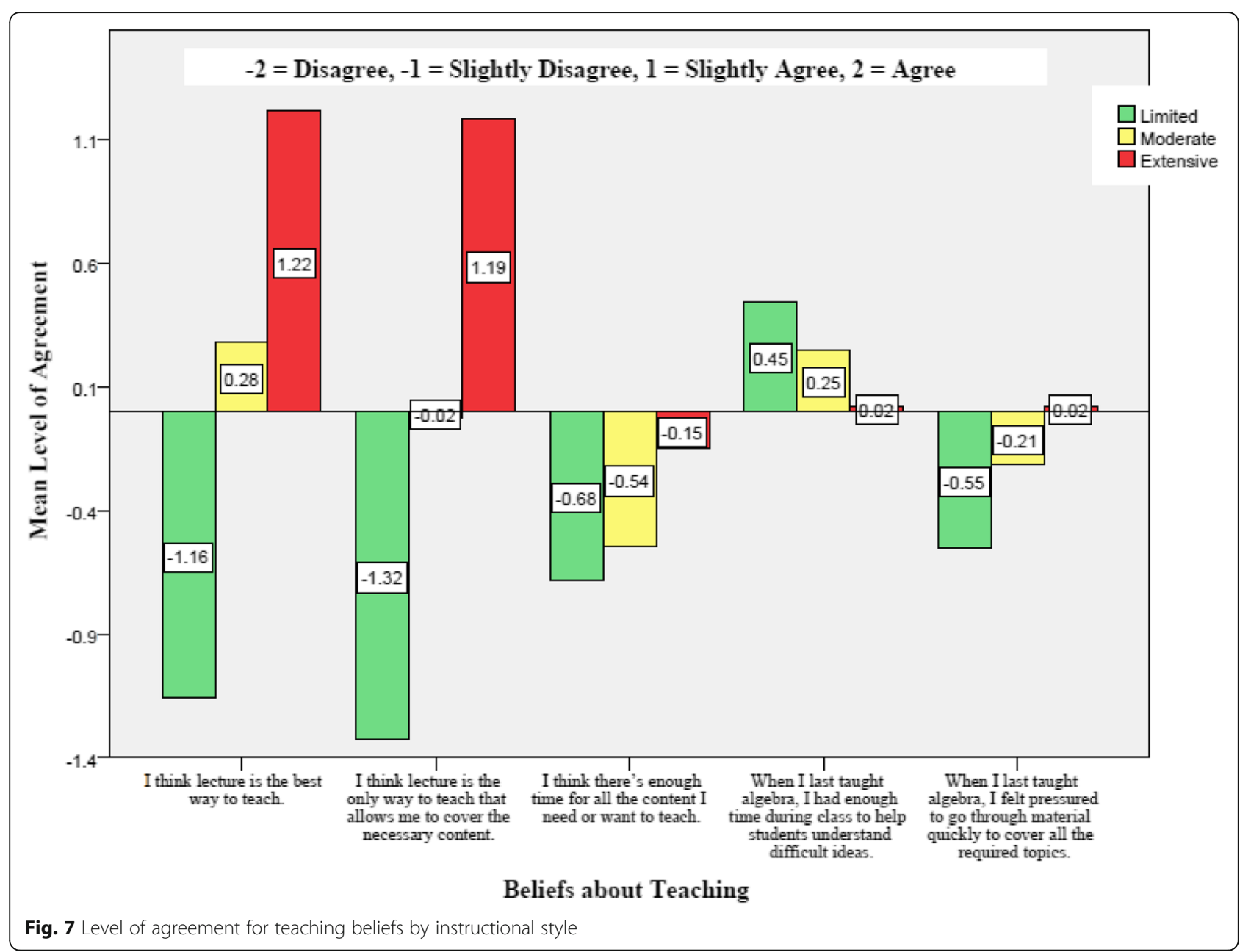

with the statements I think all students can learn advanced mathematics and I think all students can learn abstract algebra, whereas the instructors who lecture the least reported the strongest agreement with those statements. Given our data, it is impossible to determine whether instructors in the Extensive group lecture because they do not believe their students are capable of learning the material without this, or if providing more class time for students to engage in mathematics has supported Limited lecturers in developing more optimistic beliefs of student ability. Regardless, perception of student capability is an area where beliefs across the three categories of instruction differ significantly, making it an appropriate direction for further research.

Finally, in terms of level of interest in various scholarly activities (Fig. 9), all instructor groups reported very strong interest in teaching upper-division courses generally and abstract algebra specifically. However, we found significant differences by instructional approach when considering research activities. In particular, Extensive lecturers were significantly more interested in mathematical research in abstract algebra and less interested in educational research (discussing/reading about how students learn abstract algebra, research in the scholarship of teaching and learning) as compared with the Limited lecturers; the Moderate lecturers were middle-most in their mean reported interest for all 3 items.

In summary, the investigation of our second research question has yielded information that helps clarify what individual characteristics vary by instructional style. In particular, at least one significant pairwise comparison existed for 12 of the 17 items under consideration: teaching experience $(2 / 2)$, beliefs about teaching and learning $(7 / 10)$, and interest in various types of research $(3 / 5)$. (See Table 4 for details on the pairwise comparisons.) Instructors who predominantly lecture are the most experienced group, hold the strongest beliefs in favor of the appropriateness/necessity of lecture and the most limited views of their students' independent abilities, and have a stronger interest in abstract algebra research than educational research. Conversely, instructors who minimally lecture tend to be the least experienced, hold the strongest beliefs in favor of non-lecture activities and the most optimistic views of their students' 


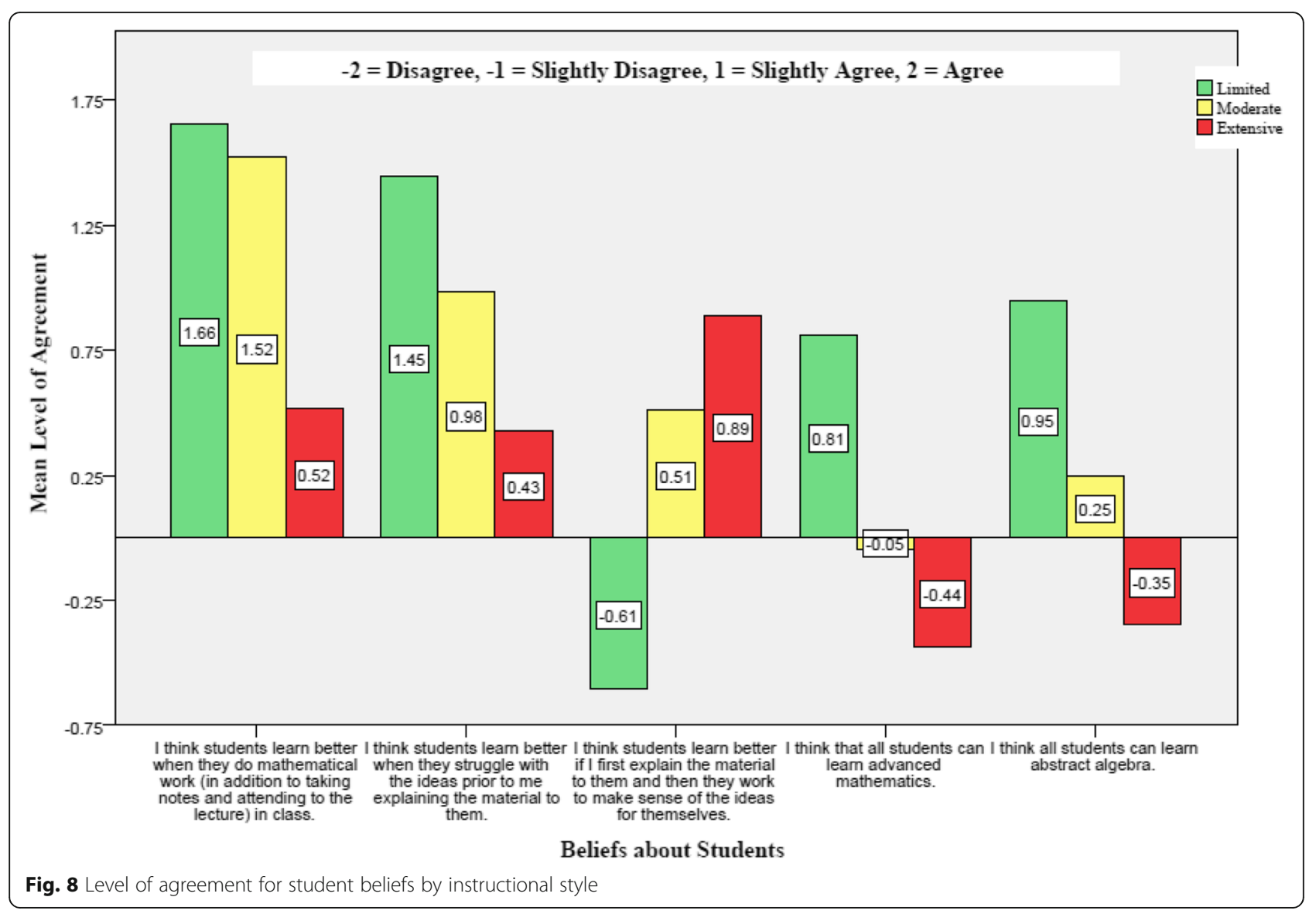

abilities, and prefer research in teaching and learning to that of abstract algebra.

\section{Research question \#3-what situational characteristics are associated with instructors who report extensive, moderate, and limited use of lecture?}

We now examine situational factors that might influence an instructor's pedagogical approach. For this analysis, we considered two sets of survey items: those that situated abstract algebra within the broader mathematics curriculum and those intended to capture respondents' perceptions of departmental support for, and institutional constraints on, instruction.

Beyond asking respondents to identify their institution type (by the terminal mathematics degree offered in their department), the survey solicited information designed to determine the course sequencing surrounding abstract algebra and the type of students enrolled in abstract algebra. Respondents selected from Yes, it is a prerequisite; Yes, it is optional; or No when asked Is there a proof-writing class that students take prior to taking your course? Similarly, instructors selected from Yes, it is required for math majors; Yes, it is optional; and No when asked Is there an abstract algebra course that follows your course? The inclusion of these items was to determine if the partner course offerings (i.e., prerequisites and follow-up courses) were related to content concerns and thus pedagogical decisions.

When considering the distribution of institution type by instructional style (Fig. 10), we found that Extensive lecturers are significantly more likely to reside at a Ph.D.-granting institution than either the Moderate $(p$ $<.001)$ or Limited ( $p=.001)$ lecturers: nearly $60 \%$ of Extensive lecturers are at $\mathrm{PhD}$-granting institutions, as compared with $18 \%$ of Limited lecturers. Furthermore, while we can see that the modal class for all institution types is Moderate, we do see a gradual rise in incidence of Extensive lecture usage as the terminal degree escalates from bachelor's (12.5\%) to master's $(25 \%)$ to doctorate $(41.77 \%)$. Collectively, these results indicate an association between institution type and instructional approach.

When considering the positioning of abstract algebra within the broader mathematics curriculum, we found little to suggest that the instructors in the various groups experienced different departmental circumstances. The distribution of responses on both the prerequisite course and follow-up course items revealed some interesting trends (see Fig. 11), but the lack of statistical significance indicated that these items are likely independent of 


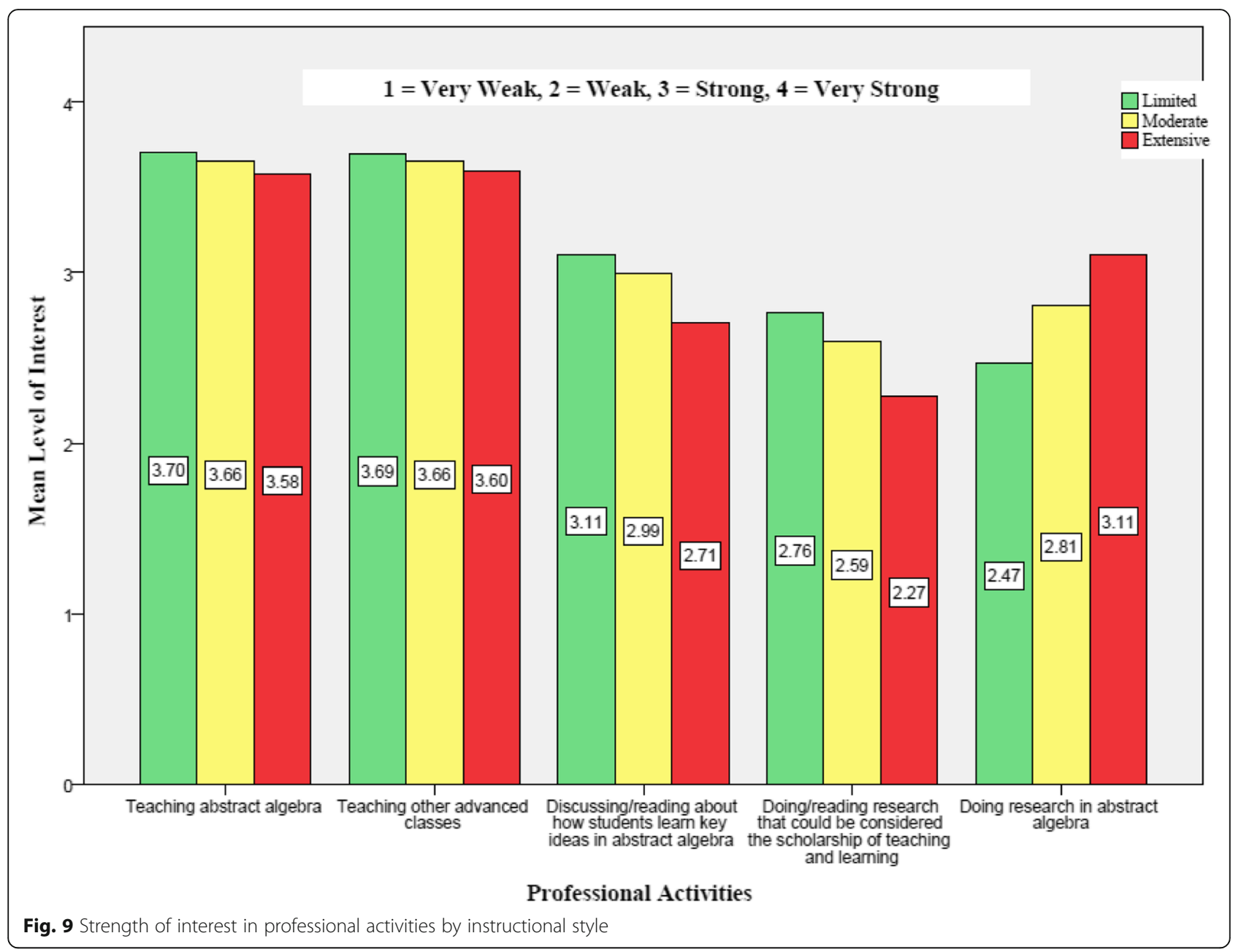

instructional approach. Limited lecturers tend to be the most likely to work in a department to require a proofbased prerequisite (79\%) and the least likely to work in one that offers a subsequent algebra course (58\%). ${ }^{9}$ Additionally, we observed that the requirement of a proofwriting prerequisite seems to be inversely related to the proportion of time spent lecturing (Limited > Moderate $>$ Extensive) and that the existence of a follow-up algebra course appears to be directly related (Limited < Moderate < Extensive); however, there were no significant pairwise comparisons in either case.

The second subset of items (Table 5) analyzed in investigation of the third research question included those questions intended to capture respondents' departmental and institutional contexts as they might relate to nonlecture pedagogies. These items focused on departmental expectations for content coverage, the availability of time for teaching and course redesign, travel support for professional development, and freedom to make changes to their abstract algebra course. This analysis yielded strikingly homogeneous responses. Not only were the mean responses by instructor group not statistically significantly different for the majority of the items, but the distributions of response patterns were nearly identical as well.

The only item (Fig. 12) that showed any significant differences across instructional type was the question $D o$ you feel like your job requirements allow you to spend as much time as you would like on teaching and preparing for class (including improving courses)? Here, we see that about $70 \%$ of Limited and Extensive lecturers reported that their job requirements allow them as much time as they would like for teaching, whereas slightly less than half of the Moderate group felt that way.

Overall, this analysis is unable to provide distinctions on situational characteristics between types of instructors, at least as they are defined here. In particular, at least one significant pairwise comparison existed for only two of the eight items under consideration. We maintain our perspective that instructional practice is constrained, meaning that instructors do not feel free to teach however they please, as they must accommodate obligations to their discipline, their institutions, their departments, and their students. Thus, we infer that these 
Table 4 Pairwise comparisons of individual characteristics by instructional style

\begin{tabular}{|c|c|c|c|c|c|}
\hline \multirow[t]{2}{*}{ Fig. } & \multirow[t]{2}{*}{ Item } & \multirow[t]{2}{*}{ Global test statistics } & \multicolumn{3}{|l|}{ Post hoc comparisons } \\
\hline & & & Extensive moderate & Extensive limited & Moderate limited \\
\hline \multirow[t]{2}{*}{6} & $\begin{array}{l}\text { How many years have you been teaching } \\
\text { upper-division mathematics courses? }\end{array}$ & $H=7.552, n=219, p=.023$ & $E>M(p=.028)$ & $E \sim L$ & $M \sim L$ \\
\hline & $\begin{array}{l}\text { How many times have you taught abstract } \\
\text { algebra? }\end{array}$ & $H=6.370, n=219, p=.041$ & $E \sim M$ & $E>L(p=.043)$ & $M \sim L$ \\
\hline \multirow[t]{5}{*}{7} & I think lecture is the best way to teach. & $H=63.391, n=215, p<.001$ & $\mathrm{E}>\mathrm{M}(p<.001)$ & $E>L(p<.001)$ & $M>L(p<.001)$ \\
\hline & $\begin{array}{l}\text { I think lecture is the only way to teach that } \\
\text { allows me to cover the necessary content. }\end{array}$ & $H=61.125, n=213, p<.001$ & $\mathrm{E}>\mathrm{M}(p<.001)$ & $E>L(p<.001)$ & $M>L(p<.001)$ \\
\hline & $\begin{array}{l}\text { I think there is enough time for all the } \\
\text { content I need or want to teach. }\end{array}$ & $H=2.215, n=216, p=.330$ & $E \sim M$ & $E \sim L$ & $M \sim L$ \\
\hline & $\begin{array}{l}\text { When I last taught algebra, I had enough } \\
\text { time during class to help students } \\
\text { understand difficult ideas. }\end{array}$ & $H=1.690, n=216, p=.430$ & $E \sim M$ & $E \sim L$ & $M \sim L$ \\
\hline & $\begin{array}{l}\text { When I last taught algebra, I felt pressured } \\
\text { to go through the material quickly to cover } \\
\text { all the required topics. }\end{array}$ & $H=3.515, n=215, p=.172$ & $E \sim M$ & $E \sim L$ & $M \sim L$ \\
\hline \multirow[t]{5}{*}{8} & $\begin{array}{l}\text { I think students learn better when they do } \\
\text { mathematical work (in addition to taking } \\
\text { notes and attending to the lecture) in class. }\end{array}$ & $H=27.508, n=214, p<.001$ & $\mathrm{E}<\mathrm{M}(p<.001)$ & $\mathrm{E}<\mathrm{L}(p<.001)$ & $M \sim L$ \\
\hline & $\begin{array}{l}\text { I think students learn better when they } \\
\text { struggle with the ideas prior to me } \\
\text { explaining the material to them. }\end{array}$ & $H=18.045, n=213, p<.001$ & $E \sim M$ & $\mathrm{E}<\mathrm{L}(p<.001)$ & $M<L(p=.016)$ \\
\hline & $\begin{array}{l}\text { I think students learn better if I first explain } \\
\text { the material to them and then they work } \\
\text { to make sense of the ideas for themselves. }\end{array}$ & $H=29.526, n=215, p<.001$ & $E \sim M$ & $\mathrm{E}>\mathrm{L}(p<.001)$ & $M>L(p<.001)$ \\
\hline & $\begin{array}{l}\text { I think that all students can learn advanced } \\
\text { mathematics. }\end{array}$ & $H=14.438, n=215, p=.001$ & $E \sim M$ & $\mathrm{E}<\mathrm{L}(p<.001)$ & $M>L(p=.015)$ \\
\hline & I think all students can learn abstract algebra. & $H=14.049, n=214, p=.001$ & $E \sim M$ & $\mathrm{E}<\mathrm{L}(p=.001)$ & $M \sim L$ \\
\hline \multirow[t]{5}{*}{9} & Interest in teaching abstract algebra. & $H=1.080, n=215, p=.583$ & $E \sim M$ & $E \sim L$ & $M \sim L$ \\
\hline & Interest in teaching other advanced classes. & $H=.498, n=214, p=.780$ & $E \sim M$ & $E \sim L$ & $M \sim L$ \\
\hline & $\begin{array}{l}\text { Interest in discussing/reading about how } \\
\text { students learn key ideas in abstract algebra. }\end{array}$ & $H=7.368, n=215, p=.025^{*}$ & $E \sim M$ & $E<L(p=.048)$ & $M \sim L$ \\
\hline & $\begin{array}{l}\text { Interest in doing/reading research that } \\
\text { could be considered the scholarship of } \\
\text { teaching and learning. }\end{array}$ & $H=7.307, n=216, p=.026^{*}$ & $E \sim M$ & $\mathrm{E}<\mathrm{L}(p=.033)$ & $M \sim L$ \\
\hline & Interest in doing research in abstract algebra. & $H=6.582, n=214, p=.037^{*}$ & $E \sim M$ & $\mathrm{E}>\mathrm{L}(p=.033)$ & $M \sim L$ \\
\hline
\end{tabular}

*As before, the family-wise error rate for the global tests was controlled by use of the Holm-Bonferroni correction by cluster for 7 and 8 items (unnecessary for the items in 6). For the items in 9, strict adherence to the FWER correction would dictate that none of the five global tests achieved statistical significance (despite $3 p$ values <.05). As this was an exploratory study, we have elected to perform post hoc tests in spite of this, but advise the reader to interpret these results with caution

results suggest that either the situational characteristics we attempted to measure (e.g., time constraints, departmental supports) are not the factors that most significantly influence pedagogical decision-making, or that our instrument was simply not designed to capture instructional differences tied to these situational characteristics.

\section{Conclusion}

In this study, we adopted the perspective that teaching is a constrained practice wherein instructors make decisions in a system governed by personal bounds and institutional constraints (Hall \& Taylor, 1996). We first sought to understand the relationships between lecture and other instructional practices. Sorting respondents by the percentage of time spent lecturing highlighted 14 instructional practices that were significantly different between at least two of the three instructional categories, with six practices being significantly different on all three pairwise comparisons. Additionally, we found great similarity within the some of the groups (i.e., Extensive lecturers, who spend more than $75 \%$ of their time lecturing, also spend the remaining $25 \%$ of their time engaged in very similar activities as other Extensive lecturers) and significant differences between each of these groups (e.g., Moderate lecturers, who spend $25-75 \%$ of their 

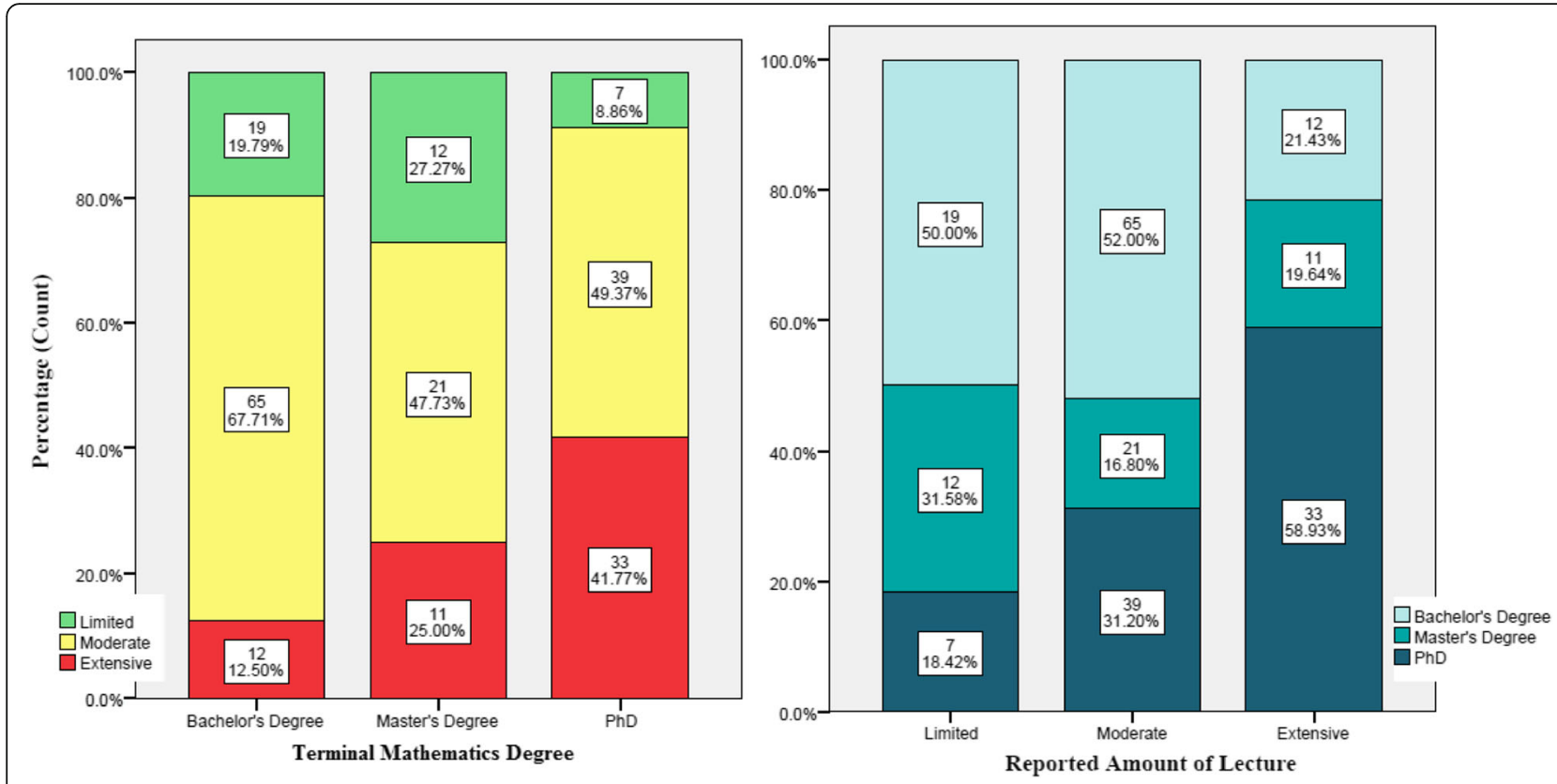

Fig. 10 Institution type by instructional style

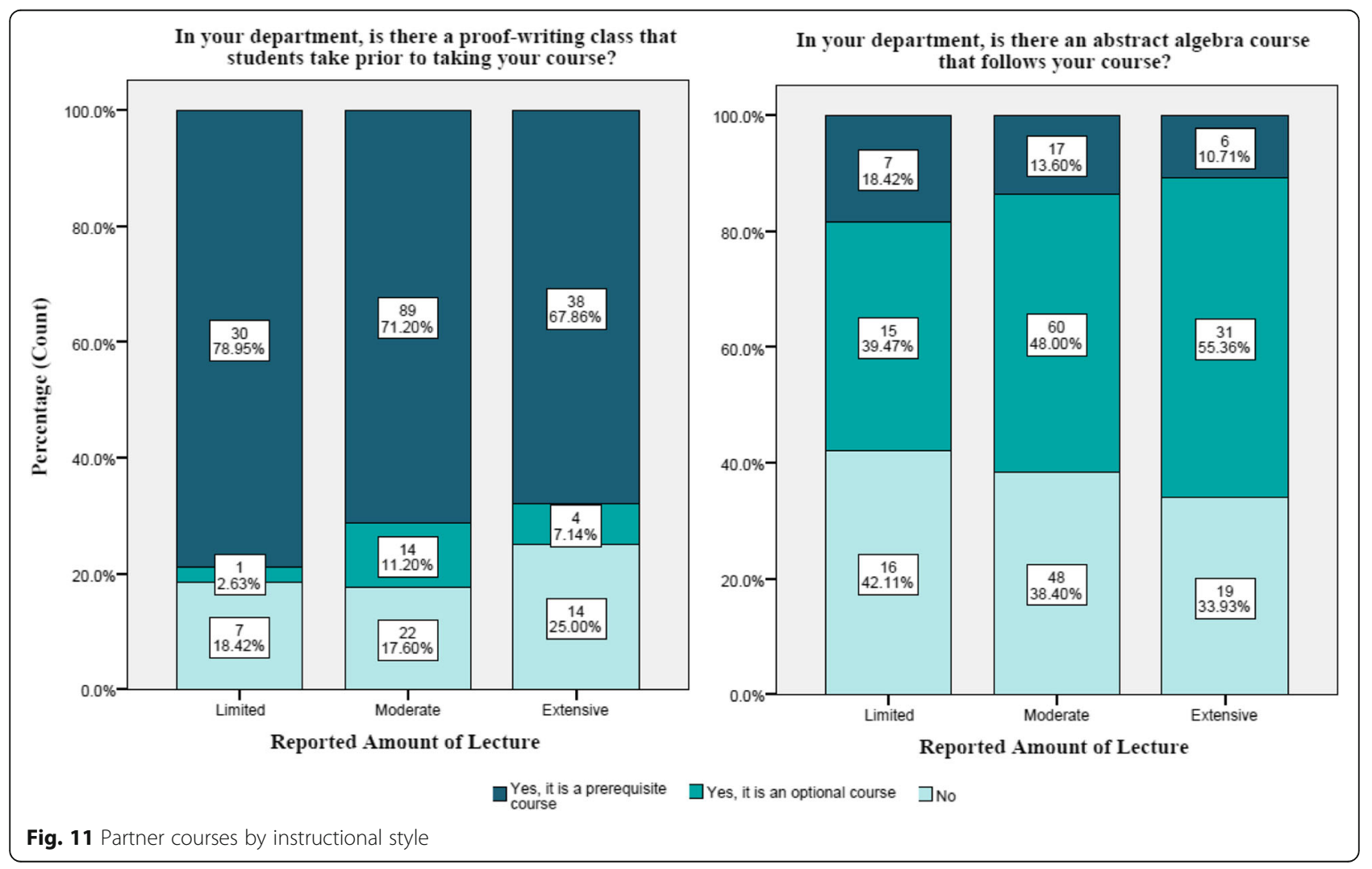


Table 5 Departmental support items cross-tabulated by instructional style

\begin{tabular}{|c|c|c|c|}
\hline Do you feel pressure from your department to cover a fixed set of material? & Yes & Maybe & No \\
\hline Limited lecturers & $28.95 \%$ & N/A & $71.05 \%$ \\
\hline Moderate lecturers & $29.75 \%$ & N/A & $70.25 \%$ \\
\hline Extensive lecturers & $30.19 \%$ & N/A & $69.81 \%$ \\
\hline $\begin{array}{l}\text { I believe I would have the freedom to make changes to the content of my course } \\
\text { (e.g., including or excluding certain topics and/or textbook changes). }\end{array}$ & Yes & Maybe & No \\
\hline Limited lecturers & $78.59 \%$ & $18.54 \%$ & $2.63 \%$ \\
\hline Moderate lecturers & $75.61 \%$ & $21.95 \%$ & $2.44 \%$ \\
\hline Extensive lecturers & $74.55 \%$ & $23.64 \%$ & $1.81 \%$ \\
\hline $\begin{array}{l}\text { I believe I would have time to plan and redesign my course in a way that would be } \\
\text { supported and valued in my annual review or P\&T process. }\end{array}$ & Yes & Maybe & No \\
\hline Limited lecturers & $36.85 \%$ & $44.74 \%$ & $18.42 \%$ \\
\hline Moderate lecturers & $36.59 \%$ & $39.84 \%$ & $23.58 \%$ \\
\hline Extensive lecturers & $38.18 \%$ & $41.83 \%$ & $20.00 \%$ \\
\hline $\begin{array}{l}\text { I believe I would have travel support to attend professional development opportunities } \\
\text { (e.g., Project NExT, MAA/AIM workshops). }\end{array}$ & Yes & Maybe & No \\
\hline Limited lecturers & $43.37 \%$ & $44.74 \%$ & $7.89 \%$ \\
\hline Moderate lecturers & $39.02 \%$ & $41.46 \%$ & $19.51 \%$ \\
\hline Extensive lecturers & $38.18 \%$ & $47.27 \%$ & $14.55 \%$ \\
\hline
\end{tabular}

$N / A$ this was not a response choice for this item

time lecturing, spend the remaining $75-25 \%$ of their time engaged in different activities than Limited lecturers).

We suggest that these findings provide some cause for optimism in terms of a move towards the types of student-centered instructional practices increasingly encouraged by education researchers and the professional communities. The wide range of instructional practices and beliefs about teaching and learning reported by Moderate lecturers (and, to some extent, the Extensive lecturers) suggests that these instructors may be open to some changes in practice, such as posing more conceptual and cognitively demanding questions, allowing some time in class for student reflection and mathematical work, or having students talk to each other prior to responding to posed questions. However, we posit that these changes cannot be introduced in opposition to instructors' core beliefs (e.g., that lecture is the best way to teach).

Meeting instructors where they are, and introducing behaviors that are commensurate with their beliefs, may be an entry point for supporting them in transitioning to more research- and evidence-based instructional practice. That is, identifying pedagogical changes that are broadly consistent with instructors' current practice and beliefs may provide the "activation energy" for a selfreinforcing cycle of changes in practice and belief leading to more student-centered instructional practices. For instance, Paoletti et al. (2018) reported on the questioning behaviors of 11 lecturers in advanced mathematics and showed that all of them regularly asked questions of the students during class. However, these questions were most commonly used to prompt students to provide a fact or the next step in a computation or proof. By capitalizing on the respondents' reported belief that students should do meaningful work in class, it may be possible to support instructors in shifting their questions to more mathematically sustainable questions, i.e., ones that better align with their beliefs.

Given our results, we believe that change efforts that either leverage beliefs that align with active learning (e.g., I think students learn better when they do mathematical work in class) or challenge beliefs that misalign with active learning (e.g., I think lecture is the best way to teach) may be particularly effective. For our respondents, we found that sorting instructors based on amount of time spent lecturing was highly discriminating in regard to personal bounds. Utilizing just this one sorting mechanism, we found significant differences in terms of beliefs about teaching, learning, students, and professional interests suggesting that personal bounds in general, and beliefs in particular, are strongly related to the decision to (not) lecture. Further, on all individual characteristic survey items, the three groups of instructors were sorted on a continuum: the Extensive and Limited groups always occupied the extreme positions on the continuum with the Moderate group in between. Such a continuum has been suggested in the research literature (e.g., Henderson \& Dancy, 2007) but has not previously been evidenced with data. 


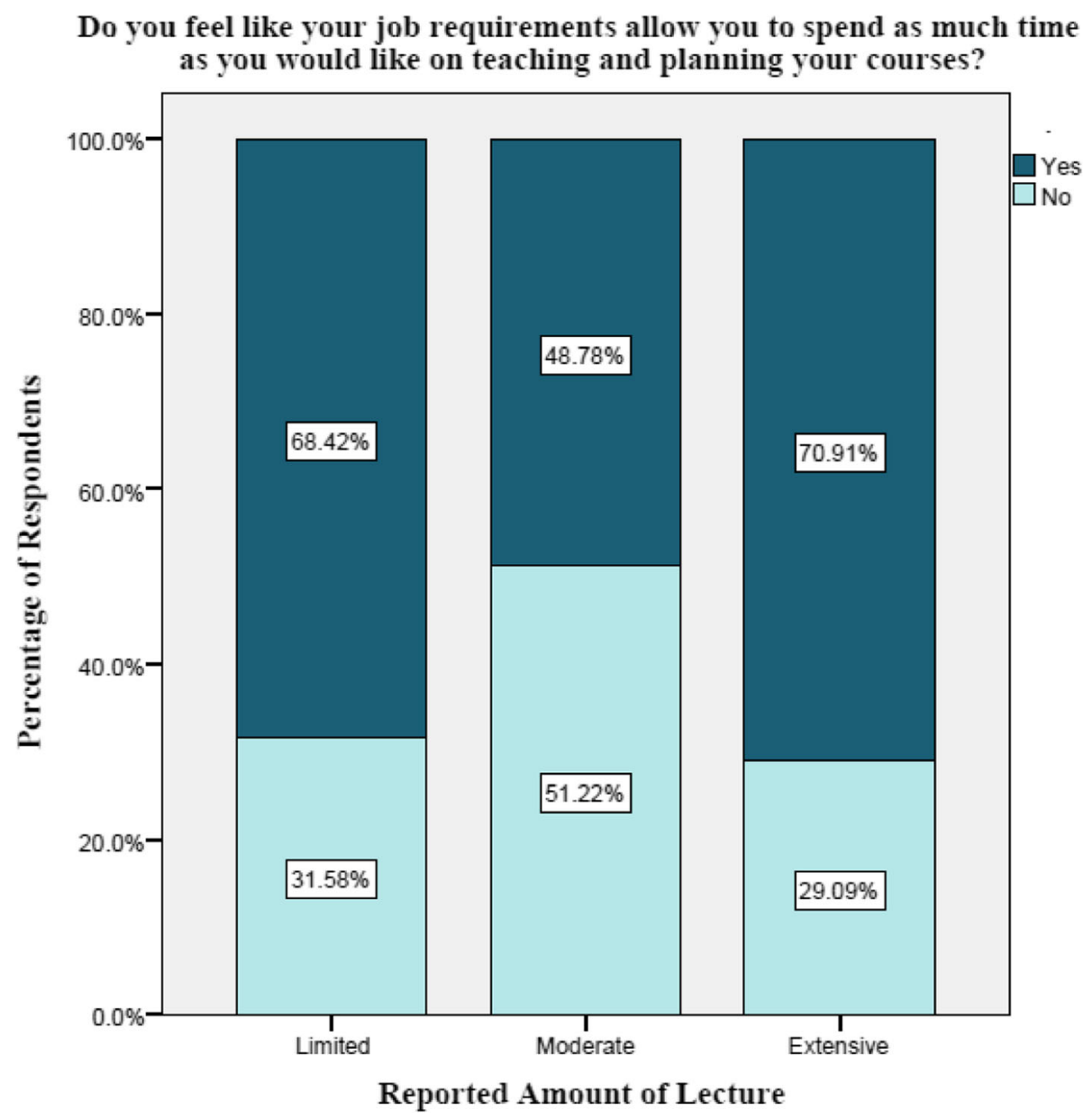

Fig. 12 Time pressure by instructional style

Moreover, this is the first large-scale report on the types of beliefs that abstract algebra faculty hold. For example, our results provide counter-evidence to the "folklore" that many instructors believe that abstract algebra is simply too hard for most students, as claimed by Leron and Dubinsky (1995). We note that even the Extensive lecturers only slightly disagree with the universal claim, I believe all students can learn abstract algebra, while both the Moderate and Limited groups are neutral and positive, respectively. Similarly, all of the respondents believe students should do mathematical work and actively think about the mathematics in class (over and above taking notes). We find all of these beliefs quite promising in terms of points of leverage for instructional change and suggest that further research is needed to explore how they might be leveraged in support of the "minimal" changes suggested above.

In terms of how institutional constraints shaped instruction, only the terminal mathematics degree offered by the department showed significant differences, although this is likely US-specific as universities are more specialized in other countries. No items related to instructional support, reinforcement from administrators, or reported perceptions of time were clearly linked to types of instruction. In fact, many of the commonly cited reasons used to justify the use of extensive lecture (e.g., pressure to cover material, no support for changes) were not significantly different across the three groups of instructors. This lack of differentiation suggests that there may be relevant institutional characteristics that have not yet been explored in the literature, and a transnational comparison might be useful in identifying them. Thus, more research needs to be done to understand what informs (abstract algebra) instructors' decisions beyond the institutional characteristics most often cited to date. For instance, investigating ways in which instructional practice is constrained and informed by a sense of responsibility to the discipline or by personal experience (as a former student oneself, perhaps) may better explain coverage concerns or reliance on lecturing than formal departmental expectations. 
The use of a national survey offered us a means for testing findings that had been generated through smaller, qualitative, interview studies. For instance, there have been a number of studies looking at a small number of instructors to better understand the instructional practices of mathematicians (e.g., Artemeva \& Fox, 2011; Fukawa-Connelly, Weber, \& Mejía-Ramos, 2017; Paoletti et al., 2018). Our dataset can now serve as a comparison to understand how the results of such studies align with reports of instruction from this national sample. Additionally, the national survey allowed us to test hypotheses and long-held claims. For instance, none of the commonly stated constraints, such as time constraints, lack of time or recognition for teaching, or content pressure, were related to instructional practice. Having this finding allows researchers to re-examine how these oftcited constraints are related to beliefs and instruction.

However, the use of a survey also presents some limitations. This includes the accuracy of self-reports of instruction, the non-response bias, and the depth at which complex systems can be captured. As summarized by Ross, McDougall, Hogaboam-Gray, and LeSage (2003), "studies examining the accuracy of teacher self-reports present mixed results" (p. 346). For instance, Mayer (1999) found that the teachers in their study were not able to consistently report the amount of time spent using specific instructional practices, whereas Hayward, Weston, and Laursen (2018) found that "when survey and observational measures are aligned, instructors' selfreported practices are aligned with observational data" (p. 732). To the extent possible, we tried to ask questions about instructional practice in ways that we believed instructors would accurately report, which typically involved fairly coarse response bins (e.g., "never, " "once or twice a class," "3+ times per class"). Ultimately, however, we do not have a way to establish the reliability of the self-reports in our study. This is true both for how accurately the instructors were able to describe the amount of time they engaged in specific practices and for the idiosyncratic ways in which terms like "lecture" and "whole class discussion" were interpreted.

Additionally, given how participants were recruited for the study (i.e., by us sending a recruiting email to the administrative assistant who then forwarded it to relevant faculty members), we are not able to speak to how much of the population completed our survey, nor are we able to take into consideration issues like non-response bias. We do however know that very few of our participants came from the same university. Thus, we did not have to address any nested structure during data analysis.

Finally, we want to acknowledge that surveys do present some challenges for capturing the complexities of personal beliefs and situational contexts-especially related to culture. We believe that this must inform the interpretation of our results, especially regarding the extent to which we failed to find relationships between situational characteristics and instructional practice. We call for more work to be done to understand how context influences practice and how that context can be measured.

\section{Endnotes}

${ }^{1}$ Here, we use the term "lecture" to refer to an instructional paradigm in which the instructor is the dominant classroom actor, who typically presents a prepared set of material to the students by orally narrating a set of written notes.

${ }^{2}$ See http://www.maa.org/cspcc for more information about the CSPCC project and a copy of the surveys.

${ }^{3}$ In the instructor survey, they were asked to respond to "Developing a definition or explaining it's [sic] evolution."

${ }^{4}$ This list of 330 universities was generated as part of the Progress through Calculus project (NFS \#1430540).

${ }^{5}$ https://www.rand.org/content/dam/rand/pubs/monograph_reports/MR1480/MR1480.appa.pdf

${ }^{6}$ It is important to note that this item was subject to interpretation. An instructor who lectures the entire class meeting but only on half of the days and an instructor who lectures half of each class meeting might both have reported (accurately) 50\%, yet these scenarios represent different classroom experiences.

${ }^{7}$ The Kruskal-Wallis test is the non-parametric alternative to ANOVA which is applicable in situations where the typical ANOVA assumptions are violated, specifically in the case of ordinal data as in this study. In this procedure, the $H$ statistic is computed based on the discrepancies among the mean rank sums of the subgroups; large values of this test statistic correspond with large discrepancies among the rank sums and indicate that the distribution of the item responses across profile categories is not the same (i.e., that the medians are different). As a point of clarification, in each of Figs. 3, 4, and 5, the Kruskal-Wallis test as described here does not compare group means, but we have chosen to display them as a means of visual reference for the sake of parallelism with other figures in this report. Median values can be seen in Table 3 .

${ }^{8}$ Note that the "Lecturing" item was used to bin the instructors, so it is shown here only for reference. We have already demonstrated differences on this item; thus, performing tests of statistical inference is non-sensical here.

${ }^{9}$ Notice, this also implies that Ph.D.-granting institutions are both the least likely to have an introduction to proofs course and the least likely to have a required second semester course in abstract algebra. 


\section{Abbreviations}

AMATYC: American Mathematics Association for Two-Year Colleges;

AMS: American Mathematical Society; ASA: American Statistical Association; MAA: Mathematical Association of America; SIAM: Society for Industrial and Applied Mathematics; US: United States

\section{Acknowledgements}

Not applicable.

\section{Authors' contributions}

The survey was developed and administered by EJ, TF, RK, and VP. RK ran the quantitative analyses and drafted the "Results and discussion" section. EJ, RK, VP, and TF were the major contributors in writing the manuscript. All authors read and approved the final manuscript.

\section{Funding}

This work was partially supported with a grant from the National Science Foundation (NSF Award \# 1431595).

\section{Availability of data and materials}

The datasets used and/or analyzed during the current study are available from the corresponding author on reasonable request.

\section{Competing interests}

The authors declare that they have no competing interests.

\section{Author details}

${ }^{1}$ Virginia Tech, Blacksburg, VA, USA. ${ }^{2}$ University of Portland, Portland, OR, USA.

${ }^{3}$ Temple University, Philadelphia, PA, USA.

Received: 15 February 2019 Accepted: 27 May 2019

Published online: 28 June 2019

\section{References}

Alcock, L. (2010). Mathematicians' perspectives on the teaching and learning of proof. In Research in Collegiate Mathematics Education VII (pp. 63-91).

American Mathematical Society. (2016). Annual Survey of Mathematical Sciences: Departmental Groupings [data file]. Retrieved from http://www.ams.org/ profession/data/annual-survey/groupings.

Artemeva, N., \& Fox, J. (2011). The writing's on the board: The global and the local in teaching undergraduate mathematics through chalk talk. Written Communication, 28(4), 345-379.

Benton, S., \& Pallett, W. (2013). Class size matters. In Inside higher Ed Retrieved from https:/www.insidehighered.com/views/2013/01/29/essay-importanceclass-size-higher-education.

Blair, R., Kirkman, E. E., \& Maxwell, J. W. (2013). Statistical abstract of undergraduate programs in the mathematical sciences in the United States (conference board of the mathematical sciences). Providence: American Mathematical Society.

Breakwell, G., Hammond, S., Fife-Schaw, C., \& Smith, J. (2006). Research methods in psychology (3rd ed.). Thousand Oaks: Sage Publications.

Calderhead, J. (1996). Teachers: Beliefs and knowledge. In D. Berliner \& R. Calfee (Eds.), Handbook of Educational Psychology (pp. 709-725). New York: Macmillan Library Reference.

Cook, J. P. (2014). The emergence of algebraic structure: Students come to understand units and zero-divisors. International Journal of Mathematical Education in Science and Technology, 45(3), 349-359.

Davidson, N., \& Gulick, F. (1976). Abstract algebra: An active learning approach. Boston: Houghton Mifflin.

Dubinsky, E., \& Leron, U. (1994). Learning abstract algebra with ISETL. New York: Springer Science \& Business Media.

Eagan, K. (2016). More student-centered? An examination of faculty teaching practices across STEM and non-STEM disciplines between 2004 and 2014. Los Angeles: Higher Education Research Institute.

Eley, M. (2006). Teachers' conceptions of teaching, and the making of specific decisions in planning to teach. Higher Education, 51, 191-214.

Ernst, D. (2016) An inquiry-based approach to abstract algebra. Retrieved on April, 15, 2016 at http://dcernst.github.io/teaching/mat411s16/materials/

Fives, H., \& Buehl, M. M. (2012). Spring cleaning for the "messy" construct of teachers' beliefs: What are they? Which have been examined? What can they tell us. APA educational Psychology Handbook, 2, 471-499.
Fukawa-Connelly, T., Weber, K., \& Mejía-Ramos, J. P. (2017). Informal content and student note-taking in advanced mathematics classes. Journal for Research in Mathematics Education, 48(5), 567-579.

Fukwa-Connelly, T., Johnson, E., \& Keller, R. (2016). Can math education research improve the teaching of abstract algebra? Notices of the AMS, 63(3), 276-281.

Gallian, J. A., Higgins, A., Hudelson, M., Jacobsen, J., Lefcourt, T., \& Stevens, T. C. (2000). Project NEXT. Notices of the AMS, 47(2), 217-220.

Hall, P. A., \& Taylor, R. C. (1996). Political science and the three new institutionalisms. Political Studies, 44(5), 936-957.

Hayward, C., Weston, T., \& Laursen, S. (2018). First results from a validation study of TAMI: Toolkit for Assessing Mathematics Instruction. In A. Weinberg, C. Rasmussen, J. Rabin, M. Wawro, \& S. Brown (Eds.), Proceedings of the $21^{\text {st }}$ annual conference on the research in undergraduate mathematics education (pp. 727-735). San Diego: Mathematical Association of America, SIGMAA on RUME.

Hayward, C. N., Kogan, M., \& Laursen, S. L. (2016). Facilitating instructor adoption of inquiry-based learning in college mathematics. International Journal of Research in Undergraduate Mathematics Education, 2(1), 59-82.

Henderson, C., \& Dancy, M. H. (2007). Barriers to the use of research-based instructional strategies: The influence of both individual and situational characteristics. Physical Review Special Topics-Physics Education Research, 3(2), 020102.

Henderson, C., \& Dancy, M. H. (2009). Impact of physics education research on the teaching of introductory quantitative physics in the United States. Physical Review Special Topics-Physics Education Research, 5(2), 020107.

Hodge, J. K., Schlicker, S., \& Sundstrom, T. (2013). Abstract algebra: An inquiry based approach. Boca Raton: CRC Press.

Hora, M. T. (2012). Organizational factors and instructional decision-making: A cognitive perspective. The Review of Higher Education, 35(2), 207-235.

Hora, M. T., \& Ferrare, J. J. (2013). Instructional systems of practice: A multidimensional analysis of math and science undergraduate course planning and classroom teaching. Journal of the Learning Sciences, 22(2), 212-257.

Ingram, P., \& Clay, K. (2000). The choice-within-constraints new institutionalism and implications for sociology. Annual Review of Sociology, 26(1), 525-546.

Isaacs, M., Bahls, P., Judson, T., Pollatsek, H., \& White, D. (2015). Course report: Abstract algebra. In C. Schumacher, M. Siegel, \& P. Zorn (Eds.), 2015 CUPM Curriculum Guide to Majors in the Mathematical Sciences Retrieved from https://www.maa.org/sites/default/files/abstractalgebra.pdf.

Johnson, E. (2018). Undergraduate mathematics instruction: Not as bad as you'd think? In A white paper commissioned by the American Association for the Advancement of Science to inform the Levers for Change working meeting (May 7-8 2018; Bethesda, MD).

Johnson, E., Caughman, J., Fredericks, J., \& Gibson, L. (2013). Implementing inquiry-oriented curriculum: From the mathematicians' perspective. Journal of Mathematical Behavior., 32(4), 743-760.

Johnson, E., Keller, R., \& Fukawa-Connelly, T. (2018). Results from a survey of abstract algebra instructors across the United States: Understanding the choice to (not) lecture. International Journal of Research in Undergraduate Mathematics Education, 4(2), 254-285.

Larsen, S., Johnson, E., \& Bartlo, J. (2013a). Designing and scaling up an innovation in abstract algebra. The Journal of Mathematical Behavior, 32(4), 693-711.

Larsen, S., Johnson, E., Weber, K. (2013b). The teaching abstract algebra for understanding project: Designing and scaling up a curriculum innovation. Journal of Mathematical Behavior, 32(4).

Lea, S. J., \& Callaghan, L. (2008). Lecturers on teaching within the 'supercomplexity'of higher education. Higher Education, 55(2), 171.

Leatham, K. R. (2006). Viewing mathematics teachers' beliefs as sensible systems. Journal of Mathematics Teacher Education, 9(1), 91-102.

Leron, U., \& Dubinsky, E. (1995). An abstract algebra story. The American Mathematical Monthly, 102(3), 227-242.

Lew, K., Fukawa-Connelly, T. P., Mejia-Ramos, J. P., \& Weber, K. (2016). Lectures in advanced mathematics: Why students might not understand what the mathematics professor is trying to convey. Journal for Research in Mathematics Education, 47(2), 162-198.

Mayer, D. P. (1999). Measuring instructional practice: Can policymakers trust survey data? Educational Evaluation and Policy Analysis, 21(1), 29-45.

McAlpine, L., Weston, C., Berthiaume, D., \& Fairbank-Roch, G. (2006). How do instructors explain their thinking when planning and teaching? Higher Education, 51(1), 125-155. 
Messick, S. (1992). Validity of test interpretation and use. In M. Alkin (Ed.), Encyclopedia of educational research (6th ed., pp. 1487-1495). New York: MacMillan.

Nardi, E. (2007). Amongst mathematicians: Teaching and learning mathematics at university level (Vol. 3). New York: Springer Science \& Business Media.

Paoletti, T., Krupnik, V., Papadopoulos, D., Olsen, J., Fukawa-Connelly, T., \& Weber, K. (2018). Teacher questioning and invitations to participate in advanced mathematics lectures. Educational Studies in Mathematics, 98(1), 1-17.

Phillip, R. (2007). Mathematics teachers' beliefs and affect. In F. Lester (Ed.), Second handbook of research on mathematics teaching and learning (pp. 257-318). Reston: NCTM.

Ross, L., McDougall, D., Hogaboam-Gray, A., \& LeSage, A. (2003). A survey measuring elementary teacher' implementation of standards-based mathematics teaching. Journal for Research in Mathematics Education, 34(4), 344-363.

Roth McDuffie, A., \& Graeber, A. O. (2003). Institutional norms and policies that influence college mathematics professors in the process of changing to reform-based practices. School Science and Mathematics, 103(7), 331-344.

Saxe, K., \& Braddy, L. (2015). A common vision for undergraduate mathematical sciences programs in 2025. Washington, D.C: Mathematical Association of America.

Schoenfeld, A. H. (1998). Toward a theory of teaching-in-context. Issues in Education, 4(1), 1-94.

Speer, N. M. (2008). Connecting beliefs and practices: A fine-grained analysis of a college mathematics teacher's collections of beliefs and their relationship to his instructional practices. Cognition and Instruction, 26(2), 218-267.

Turpen, C., Dancy, M., \& Henderson, C. (2016). Perceived affordances and constraints regarding instructors' use of Peer Instruction: Implications for promoting instructional change. Physical Review Physics Education Research, 12(1), 010116

Weber, K. (2004). Traditional instruction in advanced mathematics courses: A case study of one professor's lectures and proofs in an introductory real analysis course. The Journal of Mathematical Behavior, 23(2), 115-133.

Weber, K. (2012). Mathematicians' perspectives on their pedagogical practice with respect to proof. International Journal of Mathematical Education in Science and Technology, 43(4), 463-482.

$\mathrm{Wu}, \mathrm{H}$. (1999). The joy of lecturing - with a critique of the romantic tradition of education writing. In S. G. Krantz (Ed.), How to teach mathematics (2nd ed., pp. 261-271). Providence: American Mathematical Society.

Yoshinobu, S., \& Jones, M. G. (2012). The coverage issue. PRIMUS, 22(4), 303-316.

\section{Publisher's Note}

Springer Nature remains neutral with regard to jurisdictional claims in published maps and institutional affiliations.

\section{Submit your manuscript to a SpringerOpen ${ }^{\circ}$ journal and benefit from:}

- Convenient online submission

- Rigorous peer review

- Open access: articles freely available online

- High visibility within the field

- Retaining the copyright to your article

Submit your next manuscript at $\boldsymbol{\nabla}$ springeropen.com 